FACULTY OF

-FAMILY PLANNING

- \& REPRODUTIVE

$\stackrel{0}{0}$

要

舀

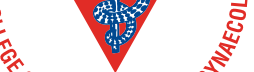

${ }^{\text {OA OBSTETRICIANS }}$ ot

\title{
Faculty of Family Planning and Reproductive Health Care
} Clinical Effectiveness Unit

A unit funded by the FFPRHC and supported by the University of Aberdeen and the Scottish Programme for Clinical Effectiveness in Reproductive Health (SPCERH) to provide guidance on evidence-based practice

\section{FFPRHC Guidance (July 2005)}

\section{The use of contraception outside the terms of the product licence}

\author{
Journal of Family Planning and Reproductive Health Care 2005; 31(3): 225-242
}

\begin{abstract}
This Guidance provides information for clinicians and women considering the use of contraception outside the terms of the product licence. A key to the grades of recommendations, based on levels of evidence, is given at the end of this document. Details of the methods used by the Clinical Effectiveness Unit (CEU) in developing this Guidance and evidence tables summarising the research basis of the recommendations are available on the Faculty website (www.ffprhc.org.uk). Abbreviations (in alphabetical order) used include: CEU, Clinical Effectiveness Unit; COC, combined oral contraception/contraceptive; DMPA, depot medroxyprogesterone acetate; ENG, etonogestrel; IUD, copper-bearing intrauterine contraceptive device; LNG-IUS, levonorgestrel-releasing intrauterine system; NET-EN, norethisterone enantate; PGD, Patient Group Direction; PIL, Patient Information Leaflet; POC, progestogen-only contraception/contraceptive; POEC, progestogen-only emergency contraception; POP, progestogen-only pill; RCT, randomised controlled trial; SPC, Summary of Product Characteristics; UPSI, unprotected sexual intercourse; WHO, World Health Organization; WHOMEC, WHO Medical Eligibility Criteria for Contraceptive Use; WHOSPR, WHO Selected Practice Recommendations for Contraceptive Use.
\end{abstract}

\section{Background}

Summaries of Product Characteristics (SPCs) provide information for clinicians on the licensed indications for contraceptives. The SPCs for most contraceptive methods are readily accessible (http://www.medicines.org.uk). SPCs provide information on how contraceptives should be administered including advice on the dose, when to start, and what to do when pills are missed or injections are late. However, SPCs often do not reflect current evidence and may be unnecessarily restrictive.

Evidence-based recommendations to guide clinicians and women on how to use contraceptive methods safely and effectively have been published by the World Health Organization (WHO).$^{1,2}$ In addition, the Faculty of Family Planning and Reproductive Health Care (FFPRHC) adapted the WHO Selected Practice Recommendations for Contraceptive Use (WHOSPR) (1st edition), using formal consensus methods, for UK use, 3,4 These Guidance documents provide evidence-based recommendations which at times are at odds with the terms of the product licences for contraceptives (e.g. advice on starting hormonal contraception). Nevertheless, the recommendations are made on the basis of systematic review of currently available evidence.

It is unlikely that, in the near future, SPCs will be altered to reflect current evidence. Confusion has resulted from conflicting information for clinicians in various sources such as SPCs, the British National Formulary, ${ }^{5}$ WHO publications 1,2 and FFPRHC Guidance. ${ }^{3,6}$ Also, manufacturers' Patient Information Leaflets (PILs) provide women with information that conflicts with alternative evidence-based sources of patient information such as fpa (Family Planning Association) leaflets.

This evidence-based Guidance provides recommendations on prescribing outside the terms of product licences and provides support for clinicians and women using contraceptive methods outside their licensed indications. Readers are also referred to the FFPRHC Clinical Standards Committee document entitled Medicines Management in Contraception, Sexual and
Reproductive Health Care Settings (currently in preparation). ${ }^{7}$

How should clinicians prescribe contraceptives for uses other than those stated in the product licence?

1 Contraceptive, sexual and reproductive health care services should ensure that their organisational policy on use of medicines outside the terms of the product licence is incorporated into clinical practice (Grade C).

2 When prescribing contraceptives outside the terms of the product licence doctors should: take an appropriate clinical history; assess a woman's priorities and preferences; discuss the evidence supporting use outside licence; document all this information clearly in the case records; and advise the woman of the benefits of informing her general practitioner (GP) (Grade C).

3 Nurse prescribers cannot prescribe medicines outside the terms of the product licence (Grade C).

4 Women should be informed when contraceptives are used outside the terms of the product licence and should be given appropriate and complementary written information in addition to the manufacturers' Patient Information Leaflets (PILs) (Grade C).

5 Patient Group Directions (PGDs) can be developed to allow nurses and other health care professionals to supply and administer contraceptives. This may include use outside the terms of the product licence provided such use is justified by current best practice. The PGD must clearly describe the status of the product and when it is being used outside licence, and should include the reasons why such use is necessary (Grade C). 
6 Pharmacists can dispense medicines outside the terms of the product licence if: the medicine is prescribed by a medical practitioner; in the best interests of the patient; and reasonable steps have been taken to ensure that the prescribing clinician knew that the medicine was to be used outside the terms of the product licence (Grade $\mathbf{C}$ ).

Definitive guidance on medicine management, The Safe and Secure Handling of Medicines: A Team Approach, was published in 2005, ${ }^{8}$ and updated the 1998 Duthie report. 9 This document highlights the need for policies on the safe use and handling of medicines throughout the National Health Service (NHS). Medicine management is an important area of clinical governance. Contraception, sexual and reproductive health care settings should ensure that there are written organisational policies for the use of medicines outside the terms of the product licence. ${ }^{8}$ This Guidance may assist in the writing of such policies.

Users have a right to information about all treatment options available to them. ${ }^{10}$ When providing information, clinicians should discuss individual needs and priorities that may influence choice. Users should be informed if medicines are being used outside the terms of the product licence and be told about the evidence, or current opinion, to support unlicensed use. To avoid conflicting information, women should be given appropriate and complementary written information that reflects current evidence (such as leaflets from the fpa) in addition to the manufacturers' PILs.

Medicines that have no licence for use in the UK can be administered, but this is usually within the context of a clinical trial and regulated by the Medicines and Healthcare products Regulatory Agency (MHRA). ${ }^{11}$ The regulations surrounding the use of unlicensed medicines are outside the scope of this Guidance.

Medicines, including contraceptives, which have a licensed indication in the UK, can be prescribed for the licensed indication but with supplementary instructions for aspects of use that fall outside the product licence. For example, the combined pill can be started up to and including Day 5 of the menstrual cycle without the need for additional contraceptive protection. ${ }^{6}$

With the exception of the levonorgestrel-releasing intrauterine system (LNG-IUS) (which is licensed for the management of idiopathic menorrhagia and protection from endometrial hyperplasia with oestrogen replacement therapy), no contraceptive method has a licensed use in the UK other than for contraception. Nevertheless, contraceptive methods are commonly prescribed in the management of medical conditions: for example, combined oral contraception (COC) for menorrhagia. ${ }^{6}$ There appears to be no distinction in the regulations between prescribing a contraceptive for contraception but with instructions different from those in the product licence and prescribing a contraceptive solely for non-contraceptive benefits.

There are no SPCs for copper-bearing intrauterine contraceptive devices (IUDs) since these are regulated as medical devices rather than medicinal products. The medical devices regulations do not require SPCs. However, under the regulations, medical devices must be ' $\mathrm{CE}$ (Kite) marked' and therefore copper IUDs (which are CE marked) can be used in the UK without having a SPC. Whilst they do not have 'a licence', such devices are required to go through a similar regulatory process, which includes assessment by one of the European Union Medicines Regulatory bodies, such as the MHRA. All IUDs have physician and user instructions.

A nurse prescriber cannot prescribe medications for use outside the terms of the product licence. When prescribing a licensed medication for use outside the terms of the product licence a clinician must:

- Be satisfied that the use of the medication outside licence meets the patient's needs better than an appropriately licensed medication.

- Be satisfied that there is sufficient evidence and/or experience of using the medicine to demonstrate its safety and efficacy.

- Take responsibility for prescribing the medication and oversee the patient's care, monitoring, and any followup, or arrange for another doctor to do so.

- Make a clear, accurate and legible record of all medicines prescribed and, when not following common practice, the reasons for prescribing the medicine.

When prescribing any medication a clinician should document in the case record details of information given to the user and the type and dose of medication prescribed. ${ }^{7}$ If the prescribing clinician is not the user's own GP and the user has been seen and treated without a referral, the importance and benefits of keeping the GP informed should be highlighted, and the GP should be informed unless the patient specifically objects. ${ }^{11}$

Patient Group Directions (PGDs) are written instructions for the supply and administration of a medicine (or medicines) where the patient need not be individually identified before presenting for treatment. ${ }^{12}$ A PGD can be developed locally by doctors, pharmacists and other health professionals and must meet certain legal criteria. Each PGD must be signed by a doctor or dentist, as appropriate, and a pharmacist, and approved by an appropriate body, usually a primary care or NHS Trust. ${ }^{12}$ PGDs can be developed to allow nurses and other health care professionals to supply and administer medicines. ${ }^{7,12}$ A PGD can include a flexible dose range so that the health care professional can select the most appropriate dose for the patient. ${ }^{12}$ A document from the Scottish Executive Health Department ${ }^{13}$ on PGDs states that the use of any medicine should be consistent with the SPCs and any relevant guidance. However, medicines used outside the terms of the product licence can be included in PGDs provided such use is exceptional, justified by current best practice, and that such a PGD clearly describes the status of the product. Each PGD should clearly state when the product is being used outside the terms of the product licence and the documentation should include the reasons why this use is necessary. ${ }^{13}$

The Royal Pharmaceutical Society (RPS) provides advice for pharmacists on the supply of medicines outside the terms of their product licence. ${ }^{14}$ The RPS states that pharmacists can prepare and dispense medicines outside the terms of the product licence in response to a prescription from a medical practitioner. ${ }^{14}$ The pharmacist must ensure that the supply is made in the best interests of the patient, and reasonable steps should be taken to ensure that the prescribing clinician knew that the medicine was to be used outside the terms of the product licence and what the consequences of that might be. ${ }^{14}$

\section{When are contraceptives prescribed outside the terms of the product licence?}

\section{Starting contraception outside product licence}

Concerns have been raised about starting contraception on any day of the cycle other than Day 1 due to risk of ovulation and subsequent pregnancy. There are wide variations in the timing of ovulation and in menstrual cycle length in normally menstruating women. ${ }^{15,16}$ Studies in small numbers of women have investigated the effects of sex hormones on ovulation, cervical mucus and endometrial receptivity. ${ }^{17,18}$ There is wide inter-individual variation in follicular growth, which can occur even during 
contraceptive cycles. If a woman has a short menstrual cycle, ovulation may occur earlier than Day 14 and the risk of ovulation with a delayed pill start is unclear. However, the risk of pregnancy is low since cycles of $<21$ days are associated with infertility. ${ }^{14,15}$ Population-based studies allow us to estimate the numbers of women who have short menstrual cycles and who may potentially be at risk of ovulation if hormonal methods are started after Day 1. The available evidence suggests that few women have short cycles, and those who do have reduced fertility. ${ }^{15,16}$

Probability plots have been used to analyse the distribution of follicular phase length (pre-ovulation) in 293 apparently ovulatory menstrual cycles, in women aged 18 to 39 years. 19 The length of the follicular phase [from the onset of menses up to, but not including, the luteinising hormone (LH) surge] was 12.9 days (95\% CI 10.3-16.3). Follicular phase length significantly decreased with increasing age, from a mean of 14.2 days in women $<18$ years to a mean of 10.4 days in women aged 40-44 years. ${ }^{19}$ A 14-day luteal phase (post-ovulation) appears to be less common than previously believed and only $10 \%$ of women (studied over 69 cycles lasting 28 days) ovulated 14 days before the onset of menses. ${ }^{20}$ Some 1740 Indian women investigated over 8304 menstrual cycles had a mean cycle length of 31.8 days (SD 6.7 days). ${ }^{21}$ Fewer than $10 \%$ had a 28 -day cycle.

University students were invited to participate in a large population-based study by keeping records of menstruation until their menopause. ${ }^{15}$ Inevitably there was a gradual fall in numbers over the years, but 25825 woman-years of menstrual experience were documented from over 2700 women. No evidence was identified to support the widely held belief that women normally have a 28 -day menstrual cycle. The first 5 to 7 years after the menarche and the last 6 to 8 years before the menopause are characterised by a variable pattern of both short and long cycles. The two decades from around the age of 20 to 40 years are associated with a relatively stable menstrual cycle, which decreases by 2 to 3 days during this time. Using these data, women with short menstrual cycles were identified. Fewer than 5\% of women aged between 15 and 44 years (and fewer than $2 \%$ of those aged 20 to 39 years) had a menstrual interval of $<20$ days. Fewer than $1 \%$ of women aged 14 to 42 years had a cycle length of $<15$ days and those who did were relatively young or old and relatively infertile..$^{22}$

Studies that have investigated serum concentrations of follicle stimulating hormone (FSH), LH, oestradiol and progesterone and menstrual cycle length have shown that long cycles (in the early reproductive years) are associated with a delayed but completely normal follicular phase. In women aged 40 to 41 years, shorter cycles were attributed to a short follicular phase. ${ }^{16}$ Previous work from this group confirmed that short cycles, with a short luteal phase, are associated with infertility. ${ }^{22}$

Most physiological studies investigate hormonal contraceptive methods starting on Day 1 and physiological evidence for later contraceptive starts is scarce but is summarised in the next section.

\section{Starting hormonal contraception outside product licence}

7 Women can be advised that, ideally, hormonal methods should be started on Day 1 of the menstrual cycle but can be started up to and including Day 5 [unlicensed for combined hormonal methods and progestogen-only pills (POPs)] without the need for additional contraception (as the risk of pregnancy is small and does not warrant the routine use of additional contraception) (Grade C).
8 Women can be advised that hormonal contraception (combined hormonal methods, POPs, implants and injectables) can be started at any other time in the cycle if it is reasonably certain they are not pregnant, but additional contraception is required for 7 days (or 2 days for POPs) (Grade C).

9 Women can be advised that the LNG-IUS can be inserted at any time in a cycle if it is reasonably certain that they are not pregnant. Additional contraceptive protection is required for 7 days if inserted after Day 7 (Grade C).

In general, a pragmatic and flexible approach to contraceptive provision should be taken based on current best evidence. Ideally, women should be encouraged to start hormonal contraception [combined hormonal pill and patch; progestogen-only pills (POPs), injectables or implants] on the first day of their menstrual cycle. However, if necessary, hormonal contraception can be started up to and including Day 5 of the menstrual cycle. In this situation, additional contraceptive protection is not required (although some women may still wish to use condoms). If a woman is $>5$ days after the start of menstruation, hormonal contraception may also be started rather than awaiting her next menstruation if it is reasonably certain she is not pregnant. A clinician can be reasonably sure that a woman is not pregnant if she has no signs or symptoms of pregnancy and meets any of the following criteria: ${ }^{2}$

- Has not had intercourse since the start of the last normal menses.

- Has been correctly and consistently using a reliable method of contraception.

- Is within 7 days after the start of normal menses.

- Is within 4 weeks postpartum.

- Is within 7 days post-abortion or miscarriage.

- Is fully or nearly fully breastfeeding, amenorrhoeic and $<6$ months postpartum.

A pregnancy test, if available, adds weight to the diagnosis (but only if $>3$ weeks since last intercourse).

Starting some hormonal contraceptives (progestogenonly implants and injectables) up to and including Day 5 of the cycle falls within the terms of the product licence. However, for other methods (POPs and combined hormonal methods) this is outside the terms of the product licence. Details of individual contraceptive methods are summarised in this section.

\section{Combined hormonal contraception}

The SPCs for COCs suggest they should be started on Day 1 of the menstrual cycle. ${ }^{23-29}$ If the Day 1 start is missed, some SPCs advise delaying the start until Day 5, and in these circumstances condoms are advised for 7 days. Some SPCs advise condoms for 7 days if starting COCs on any day other than Day 1.27,29-32

The SPC for the transdermal combined contraceptive patch suggests starting on Day 1. If starting after this time, condoms are advised for 7 days. ${ }^{33}$

Most evidence on risk of ovulation with combined hormonal contraceptives relates to COC. Nevertheless, WHO Medical Eligibility Criteria for Contraceptive Use (WHOMEC) extrapolates all information regarding COCs to the transdermal combined contraceptive patch.

COCs act primarily by reducing gonadotrophins, thus inhibiting ovulation. ${ }^{18}$ Seven consecutive COCs are required to inhibit ovulation and the remaining COCs maintain anovulation. The COC also has effects on cervical mucus and the endometrium, which contribute to 


\section{CEU GUIDANCE}

Table 1 Combined hormonal contraception: licensed and unlicensed use

\begin{tabular}{|c|c|c|}
\hline Starting time & $\begin{array}{l}\text { Licensed use as in the Summary of Product } \\
\text { Characteristics (SPC) }\end{array}$ & Evidence-based use outside the terms of the product licence \\
\hline \multicolumn{3}{|c|}{ Combined oral contraception (COC) } \\
\hline First use & $\begin{array}{l}\text { Start on Day 1; no additional method required. Start } \\
\text { after Day } 1 \text { up to Day 5; additional method required } \\
\text { for } 7 \text { days }\end{array}$ & $\begin{array}{l}\text { Ideally, start on Day } 1 \text { of the menstrual cycle. If necessary can start up to } \\
\text { and including Day } 5 \text { without additional method. Start after Day } 5 \text { when } \\
\text { reasonably certain* the woman is not pregnant, additional method is } \\
\text { required for } 7 \text { days. }\end{array}$ \\
\hline $\begin{array}{l}\text { Following abortion or } \\
\text { miscarriage }\end{array}$ & $\begin{array}{l}\text { Start immediately following first-trimester abortion. } \\
\text { (No advice given for second trimester.) }\end{array}$ & $\begin{array}{l}\text { Start on day of surgical or second part of a medical abortion (induced or } \\
\text { spontaneous }<24 \text { weeks); no additional method required. If started }>7 \\
\text { days after abortion an additional method required for } 7 \text { days. }\end{array}$ \\
\hline $\begin{array}{l}\text { Postpartum not } \\
\text { breastfeeding }\end{array}$ & $\begin{array}{l}\text { Start on Day } 21 \text { postpartum; no additional method } \\
\text { required. }\end{array}$ & $\begin{array}{l}\text { Start on Day } 21 \text { for immediate contraceptive protection. If started after } \\
\text { Day } 21 \text {, additional method required for } 7 \text { days. }\end{array}$ \\
\hline Breastfeeding & Not recommended. & $\begin{array}{l}\text { Ideally, start }>6 \text { months postpartum. If other methods are unacceptable, } \\
\text { then may be started between } 6 \text { weeks and } 6 \text { months postpartum. }\end{array}$ \\
\hline Missed pills & $\begin{array}{l}\text { ( }>36 \text { hours have elapsed since the last pill was taken.) } \\
\text { Additional method required for } 7 \text { days. }\end{array}$ & $\begin{array}{l}\text { If three } 30-35 \mu \mathrm{g} \text { EE pills are missed at any time (or if two } 20 \mu \mathrm{g} \text { EE } \\
\text { pills are missed): the last missed pill should be taken as soon as } \\
\text { remembered; continue daily pill taking; additional method for } 7 \text { days } \\
\text { (see Figure 1). } \\
\text { If COCs are missed in Week } 1 \text { (the pill-free interval has been } \\
\text { extended). If UPSI occurred in the pill-free week or in Week } 1 \text { of } \\
\text { pill taking, EC indicated. } \\
\text { If COCs are missed in Week 3, the pill-free week should be omitted. }\end{array}$ \\
\hline
\end{tabular}

Combined contraceptive patch
First use $\quad$ Start on Day 1; no additional method required

Start up to and including Day 5 without additional method. Start after Day 5 if it is reasonably certain* the woman is not pregnant; additional method required for 7 days.

Following abortion or Start immediately following abortion or miscarriage miscarriage $\quad$ at <20 weeks' gestation; no additional method

Start on day of surgical or second part of a medical abortion (induced
or spontaneous $<24$ weeks); no additional method required. If started $>7$ required. If abortion at $>20$ weeks, start 21 days later. $\quad$ days after abortion an additional method required for 7 days. No advice about additional method.)

Start on Day 21 for immediate contraceptive protection. If started after $\begin{array}{lll}\begin{array}{l}\text { Postpartum not } \\ \text { breastfeeding }\end{array} & \begin{array}{l}\text { Start no sooner than } 4 \text { weeks postpartum; additional } \\ \text { method required for } 7 \text { days. }\end{array} & \begin{array}{l}\text { Start on Day } 21 \text { for immediate contraceptive pro } \\ \text { Day 21, additional method required for 7 days. }\end{array}\end{array}$

* Reasonably certain the woman is not pregnant: has not had intercourse since the last normal menses; has been correctly and consistently using a reliable method of contraception; is within 7 days after normal menses; is within 4 weeks postpartum; is within 7 days post-abortion or miscarriage; is fully or nearly fully breastfeeding, amenorrhoeic and $<6$ months postpartum. Pregnancy testing adds weight to the diagnosis. COC, combined oral contraception; EC, emergency contraception; EE, ethinylestradiol; UPSI, unprotected sexual intercourse.

contraceptive efficacy. Studies in primates have shown that the COC can effectively inhibit ovulation even when started up to and including Day 6. ${ }^{34}$ By Day 6, selection of the dominant follicle has occurred; but COC use on Day 6 prevents the pre-ovulatory gonadotrophin surge as effectively as if started on Day 1 . Oestradiol and progesterone concentrations were effectively inhibited when COC was commenced on Day 6. Although the contraceptive effects of COC on cervical mucus are less important than inhibition of ovulation, these may provide protection from sperm penetration within 48 hours.

A randomised, single-blind study investigated the development of ovarian follicles and subsequent ovulation in women starting a monophasic, low-dose COC on Days 1,4 or 7 of the menstrual cycle. ${ }^{17}$ Women were followed up within 3 days of the onset of menstruation and on Days 7, 14, 21 and 28. Transvaginal ultrasonography was performed to assess follicular size. Serum progesterone was assessed on Days 21 and 28. Follow-up assessments were made on 85 women of 130 initially enrolled. This study showed that ovarian follicular development occurs despite COC use. However, the ovaries appear quiescent by Day 21, even when starting COC on Day 7. Follicular growth was more likely in women starting on Day 7 compared to those with Day 1 or 4 starts. Nevertheless, despite evidence of follicular activity, there was no evidence of ovulation with a Day 7 start. Ovulation was identified (by raised serum progesterone concentration on Day 21 or 28) in two women with a Day 1 start, in one woman with a Day 4 start, and no women with a Day 7 start. A larger study would be required to identify small differences between the different start date regimens.

An earlier cohort study correlated hormonal and ultrasound parameters in COC cycles in 22 women. ${ }^{18}$ Women were divided into two groups starting a triphasic COC on Day 1 or Day 5. Inhibition of follicular growth was less if COC was started on Day 5. Nevertheless, there was no evidence of a gonadotrophin surge or ovulation in either group.

The $\mathrm{WHO}^{2}$ and UK version of $\mathrm{WHOSPR}^{3}$ recommend that $\mathrm{COC}$ can be started up to and including Day 5 of the menstrual cycle, without the need for additional contraception (unlicensed) (Table 1). The available evidence supports this recommendation for combined hormonal methods. ${ }^{2,3}$ In addition, the CEU supports starting combined hormonal methods at other times in the cycle if it is reasonably certain that the woman is not pregnant (unlicensed). In this circumstance, additional contraception is advised for 7 days (Table 1). ${ }^{6}$ These starting regimens are supported in PILs from fpa.

\section{Progestogen-only pills}

POPs containing levonorgestrel, norethisterone and etynodiol diacetate work by thickening cervical mucus, delaying ovum transport, inhibiting ovulation, and providing an endometrium hostile to implantation. 35 Sixteen women were randomly allocated to take levonorgestrel pills or norethisterone pills 2-3 days before ovulation. ${ }^{36}$ Cervical mucus quality and sperm 
CEU GUIDANCE

Table 2 Progestogen-only contraception: licensed and unlicensed use

\begin{tabular}{|c|c|c|}
\hline Starting time & $\begin{array}{l}\text { Licensed use as in the Summary of Product } \\
\text { Characteristics (SPC) }\end{array}$ & Evidence-based use outside the terms of the product licence \\
\hline \multicolumn{3}{|c|}{ Progestogen-only pills (POPs) } \\
\hline $\begin{array}{l}\text { Following abortion or } \\
\text { miscarriage }\end{array}$ & $\begin{array}{l}\text { Start immediately following first-trimester } \\
\text { abortion or miscarriage. (No advice given for } \\
\text { second trimester.) }\end{array}$ & $\begin{array}{l}\text { Start on day of surgical or second part of medical abortion (induced or } \\
\text { spontaneous }<24 \text { weeks); no additional method required. If started }>7 \\
\text { days after abortion an additional method required for } 2 \text { days. }\end{array}$ \\
\hline $\begin{array}{l}\text { Postpartum not } \\
\text { breastfeeding }\end{array}$ & $\begin{array}{l}\text { Start on Day } 21 \text { postpartum; no additional } \\
\text { method required. }\end{array}$ & $\begin{array}{l}\text { Contraception is not required before Day } 21 \text { postpartum. Ideally start on } \\
\text { Day } 21 \text { postpartum for immediate contraceptive protection. Can be } \\
\text { started before Day } 21 \text { if requested. If started after Day } 21 \text {, additional } \\
\text { method required for } 2 \text { days. }\end{array}$ \\
\hline Breastfeeding & $\begin{array}{l}\text { No advice given. Micronor }{ }^{\circledR} \text { advice suggests } \\
\text { waiting until infant weaned. }\end{array}$ & $\begin{array}{l}\text { Start on or before Day } 21 \text { postpartum for immediate contraceptive } \\
\text { protection. If started after Day 21, additional method required for } \\
2 \text { days. }\end{array}$ \\
\hline & $\begin{array}{l}\text { Desogestrel pill is missed if }>36 \text { hours } \\
\text { since last pill (i.e. } 12 \text { hours late). Additional } \\
\text { method required for } 7 \text { days. }\end{array}$ & $\begin{array}{l}\text { Desogestrel-only pill is ' } m i s s e d \text { ' if }>36 \text { hours since last pill (i.e. } 12 \text { hours } \\
\text { late). Missed pill should be taken as soon as remembered; continue daily } \\
\text { pill taking; an additional method required for } 2 \text { days. EC is indicated if } \\
\text { UPSI has occurred in the } 2 \text { days since missing POPs. }\end{array}$ \\
\hline
\end{tabular}

Progestogen-only implants

First use Initiate between Days 1 and 5. (No mention of additional methods.)

Following abortion or Start immediately following a first-trimester abortion. miscarriage $\quad$ Following a second-trimester abortion, start between Days 21 and 28. If started after Day 28, additional Days 21 and 28 . If started after Day 28 , additional
method required for 7 days. (No advice given for miscarriage.)
Can start up to and including Day 5 without additional method. Start after Day 5 if it is reasonably certain* the woman is not pregnant; additional method for 7 days.

Start on day of surgical or second part of a medical abortion (induced or spontaneous $<24$ weeks); no additional method required. If started $>7$ days after abortion an additional method required for 7 days.

Start between Days 21 and 28 postpartum for immediate contraceptive protection. If started after Day 28 , additional method required for 7 days. Can be started before Day 21 but problematic bleeding can occur.

Start between Days 21 and 28 postpartum for immediate contraceptive protection. If started after Day 28, additional method required for 7 days.

Ideally start on Day 1 of the cycle. Can start up to and including Day 5 without additional method. Start after Day 5 if reasonably certain* the woman is not pregnant; additional method required for 7 days.

Start on day of surgical or second part of a medical abortion (induced or spontaneous $<24$ weeks) no additional method required. If started $>7$ days after abortion an additional method required for 7 days.

Give DMPA within 5 days postpartum. Prolonged heavy bleeding can occur. NET-EN can be used immediately after birth.

Ideally start DMPA from 6 weeks postpartum. If other methods are unacceptable, then injection may be given $<6$ weeks postpartum but ideally not before Day 21 .

Repeat DMPA should be given every 12 weeks and repeat NET-EN every 8 weeks. DMPA can be given up to 2 weeks early ( 10 weeks) or 2 weeks late (14 weeks) after the last injection without the need for additional method. NET-EN can be given up to 2 weeks early ( 6 weeks) or up to 2 weeks late (10 weeks) without the need for additional method. If DMPA and NET-EN are $>2$ weeks late, contraceptive protection may be lost and protocols should be developed locally to guide women and clinicians in deciding on need for EC and timing of next injection.

* Reasonably certain the woman is not pregnant. has not had intercourse since the last normal menses; has been correctly and consistently using a reliable method of contraception; is within 7 days after normal menses; is within 4 weeks postpartum; is within 7 days post-abortion or miscarriage; is fully or nearly fully breastfeeding, amenorrhoeic and $<6$ months postpartum. Pregnancy testing adds weight to the diagnosis. DMPA, depot medroxyprogesterone acetate; EC, emergency contraception; NET-EN, norethisterone enantate; POP, progestogen-only pill; UPSI, unprotected sexual intercourse. 
penetrability were significantly reduced 12 hours after administration. Within 2 days of initiating POPs, cervical mucus prevents sperm penetration into the upper reproductive tract.

The SPCs for POPs containing levonorgestrel, norethisterone and etynodiol diacetate suggest starting on Day 1.37-42. Some SPCs suggest condoms for 739,42 or 14 days $37,40,41$ during the first cycle of pill taking, even when starting on Day 1. Others suggest condoms for 7 days if starting after Day 1.43

The desogestrel-only pill works primarily by inhibiting ovulation. ${ }^{44}$ In addition, as for other POPs, there is thickening of cervical mucus and endometrial changes. ${ }^{45}$ Recent randomised controlled trials (RCTs) comparing the desogestrel-only pill to a levonorgestrel-only pill have shown that ovulation is inhibited in $97 \%$ and $60 \%$ of cycles, respectively. ${ }^{46}$ The SPC for the desogestrel-only POP suggests that it has to be started on Day 1 and that additional contraceptive protection is required for 7 days if starting after Day 1.47

Women should be encouraged to start all POPs on the first day of the menstrual cycle. However, as a result of the rapid effect on cervical mucus, it is unlikely that a Day 5 POP start in women with normal menstrual cycles would compromise contraceptive efficacy. The CEU supports recommendations from $\mathrm{WHO}^{2,3}$ that, if necessary, POPs can be started up to and including Day 5 without the need for additional contraceptive protection (unlicensed). In addition, POPs can be started after this time if it is reasonably certain that the woman is not pregnant. In this situation the CEU advise that additional contraceptive protection is required for 2 days (unlicensed) (Table 2). ${ }^{3}$

Manufacturers' PILs do not support this advice. The CEU suggests that fpa leaflets, which do reflect this current advice, are given to women in addition to the PIL.

\section{The progestogen-only implant}

Serum etonogestrel (ENG) concentrations rapidly rise within 8 hours of insertion of the etonogestrel-only implant (Implanon ${ }^{\circledR}$ ). Serum concentrations of ENG at 8 hours post-insertion $(265.9 \mathrm{pg} / \mathrm{ml})$ are higher than concentrations identified after 1 year of use $(196 \mathrm{pg} / \mathrm{ml})$ when ovulation is notably rare. ${ }^{48}$ Ovulation is likely to be inhibited quickly following insertion. The SPC advises initiation between Days 1 and 5 of the cycle. ${ }^{49}$

The WHOSPR supports initiation of the progestogenonly implant up to and including Day 7 without the need for additional contraceptive protection. ${ }^{2}$ Nevertheless, the CEU supports the FFPRHC UK version of this document which suggests, as for other hormonal contraceptive methods, that when necessary progestogen-only implants can be inserted up to and including Day 5 (licensed) without the need for additional contraceptive protection. ${ }^{3}$ The progestogen-only implant can be inserted at other times in the cycle if it is reasonably certain that the woman is not pregnant but additional contraceptive protection is advised for 7 days following insertion (unlicensed) (Table 2).

\section{Progestogen-only injectables}

The progestogen-only injectables available in the UK are depot medroxyprogesterone acetate (DMPA) and norethisterone enantate (NET-EN). Most evidence identified relates to DMPA. In a small cohort study of women starting DMPA between Days 8 and 13, investigators attempted to identify ovulation by ultrasound follicular rupture and raised progesterone concentrations. ${ }^{50}$ Women receiving DMPA on Days 8 or 9 showed no evidence of ovulation. Ovulation occurred in one of five women treated on Day 10; in four of ten women treated on Days 11 and 12; and four of five women treated on Day 13.50 This evidence suggests that a Day 7 start for DMPA is safe. This study also found that DMPA caused profound changes in cervical mucus. ${ }^{51}$ Little change in cervical mucus is evident at 6 hours, but $90 \%$ of women had a poor cervical score at 24 hours. By 3 days, all but one woman (97\%) had a poor cervical mucus score. However, sperm penetration was not completely inhibited by Day 3 and one woman still had maximal sperm penetration. Peak serum medroxyprogesterone acetate (MPA) concentrations are identified at 24 hours post-administration whilst peak concentrations following oral progestogen administration are at 1-2 hours. ${ }^{35}$ The SPC for DMPA suggests administration in the first 5 days of the cycle without the need for condoms. 52 The SPC for NET-EN does not advise when during the menstrual cycle to start. ${ }^{53}$ The SPC for NET-EN suggests it can be used as short-term contraception but duration of use is not specified. ${ }^{53}$ Nevertheless, the SPC suggests that one use for NET-EN is to provide contraception for a woman awaiting her partner's vasectomy to become effective, which can take many months.

WHOSPR recommends that progestogen-only injectables can be started up to and including Day 7 of the cycle without the need for additional contraceptive protection. ${ }^{2}$ The CEU supports the FFPRHC UK version of the WHOSPR, which suggests that, as for combined hormonal contraception and POPs, if necessary progestogen-only injectables can be given up to and including Day 5 (DMPA licensed) without the need for additional contraceptive protection. ${ }^{3}$ Progestogen-only injectables can be started at other times in the cycle (unlicensed) if it is reasonably certain the woman is not pregnant but additional contraceptive protection is required for 7 days (Table 2). ${ }^{3}$

The levonorgestrel-releasing intrauterine system

The LNG-IUS is licensed for contraception, the management of idiopathic menorrhagia and protection from endometrial hyperplasia with oestrogen replacement therapy. ${ }^{54}$ The main contraceptive effect of the LNG-IUS is due to local effects on the endometrium from $20 \mu \mathrm{g}$ levonorgestrel released every 24 hours. ${ }^{55}$ Ovulatory cycles with follicular rupture usually occur. Functional and histological changes are evident within 1 month of insertion. 56

The SPC suggests insertion of the LNG-IUS within 7 days of the onset of menstruation. ${ }^{54}$ No mention is made of additional contraceptive protection if inserted during this time. The CEU supports the WHOSPR recommendations that the LNG-IUS can be inserted at any time in the first 7 days after the start of menstruation and not only during menstruation (licensed). ${ }^{2}$ If inserted up to and including Day 7 no additional contraceptive protection is required. If necessary the LNG-IUS can be inserted at any other time in the cycle, at the woman's convenience, if it is reasonably certain that she is not pregnant (unlicensed). ${ }^{2}$ In this situation additional contraceptive protection is required for 7 days (Table 3 ).

\section{Starting non-hormonal contraception}

10 Women can be advised that an IUD can be inserted at any time in the menstrual cycle if it is reasonably certain she is not pregnant (Grade C). 
Table 3 Intrauterine contraception: licensed and unlicensed use

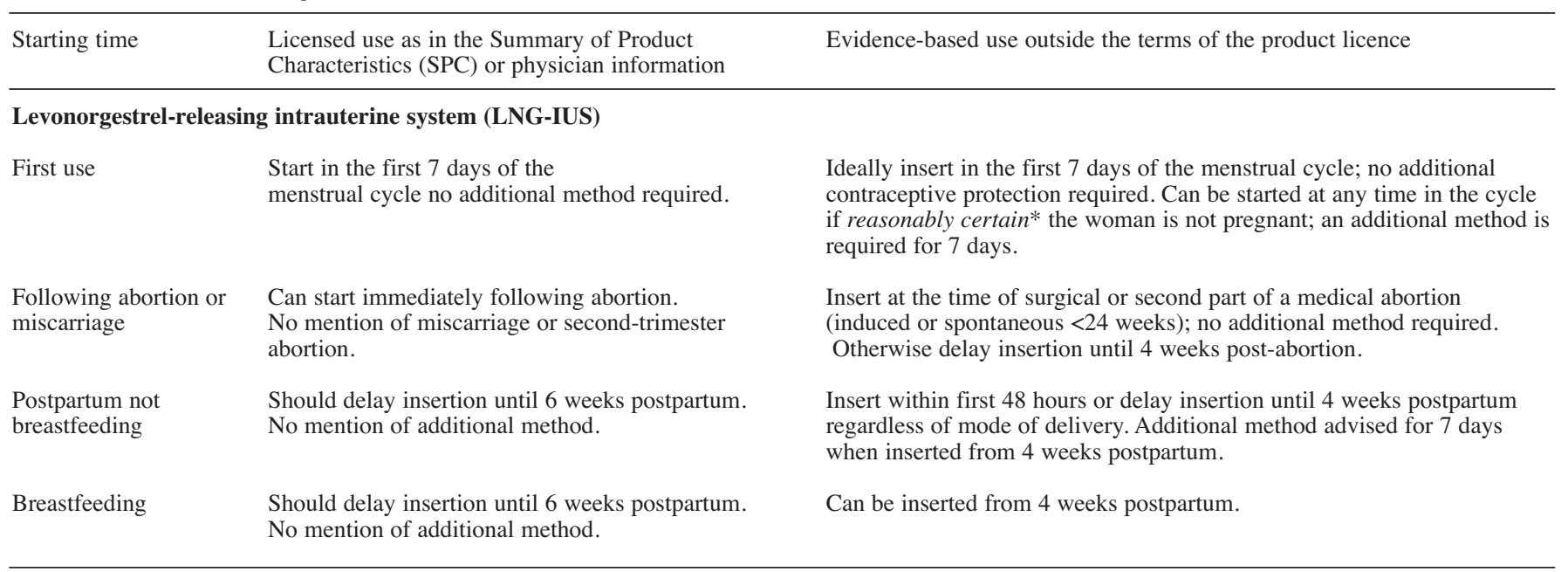

Copper intrauterine device (IUD) $\dagger$ First use $\quad \begin{aligned} & \text { Can start an IUD in the first } 7 \text { days of the menstrual } \\ & \text { cycle with no additional contraception required. }\end{aligned}$ $\begin{array}{ll}\text { Following termination } & \text { Insert immediately following first-trimester TOP. } \\ \text { of pregnancy or } & \text { No mention of miscarriage or second-trimester TOP }\end{array}$ miscarriage

Postpartum not Delay insertion of an IUD until 6 weeks postpartum. breastfeeding No additional contraception required.

Breastfeeding

No mention of use in breastfeeding women

Emergency

contraception
Advice unclear
Can be inserted at any time in the cycle if it is reasonably certain* she is not pregnant; no additional contraceptive protection is required.

Insert at the time of surgical abortion or on the day of the second part of a a medical abortion (induced or spontaneous $<24$ weeks; no additional contraception required. Otherwise delay insertion until 4 weeks post-abortion; no additional contraceptive protection required.

Start immediately postpartum and within first 48 hours or delay insertion until 4 weeks postpartum regardless of mode of delivery. Additional contraception is advised for 7 days when inserted from 4 weeks postpartum.

Start immediately postpartum and within first 48 hours or delay insertion until 4 weeks postpartum regardless of mode of delivery.

Can be inserted up to 5 days after the first episode of UPSI. Can be inserted up to 5 days after the earliest expected date of ovulation (up to Day 19 in a regular 28-day cycle) regardless of the number of episodes of UPSI.

* Reasonably certain the woman is not pregnant: has not had intercourse since the last normal menses; has been correctly and consistently using a reliable method of contraception; is within 7 days after normal menses; is within 4 weeks postpartum for non-lactating women; is within 7 days post-abortion or miscarriage; is fully or nearly fully breastfeeding, amenorrhoeic and $<6$ months postpartum. Pregnancy testing adds weight to the diagnosis. $†$ Copper IUDs do not have to go through the same processes as other contraceptive methods to be licensed for use in the UK. If they have a CE Kitemark they can be used. SPCs exist for LNG-IUS but are limited for copper IUDs. Physician and user information accompanies these devices. It is not entirely clear if use of IUD outside licence is an appropriate description. EC, emergency contraception; IUD, intrauterine device; LNG-IUS, levonorgestrel-releasing intrauterine system; TOP, termination of pregnancy; UPSI, unprotected sexual intercourse.

\section{The copper-bearing intrauterine contraceptive device} The copper IUD works primarily by inhibition of fertilisation due to the toxic effects of copper on ovum and sperm. ${ }^{57-59}$ A systematic review indicated that both prefertilisation (toxic effects) and post-fertilisation effects (preventing implantation) contribute to efficacy. 55 As a result of this toxic effect, the copper IUD can work immediately after insertion. If fertilisation has already occurred, an IUD can be inserted to prevent implantation, its secondary mode of action.

Product information for the Nova-T ${ }^{\circledR} 380$ (as an example) suggests insertion during or shortly after menstruation, and if pregnancy is excluded it may be inserted any time in the cycle. 60

The CEU supports the WHOSPR and FFPRHC UK version which suggests that an IUD can be inserted at any time in the cycle if it is reasonably certain that the woman is not pregnant (Table 3), ${ }^{2,3}$

A copper IUD can be used as emergency contraception (EC) and inserted up to 5 days after the first episode of unprotected sexual intercourse (UPSI). 2,61 An IUD can also be inserted as EC up to 5 days after the expected date of ovulation in a woman with a regular menstrual cycle (i.e. up to and including Day 19 in a regular 28-day cycle) (Table 3).,2,61

\section{Starting contraceptives in special circumstances}

Advice on starting hormonal contraception in special circumstances [such as following spontaneous or induced abortion, postpartum, when breastfeeding or following use of progestogen-only emergency contraception (POEC)] is covered in this section. Some advice was published by the CEU in previous Guidance and is summarised in Tables $1-3.6,62$

Following miscarriage or abortion (<24 weeks' gestation)

11 Women can be advised that all contraceptive
methods can be started immediately following
miscarriage or induced abortion occurring at $<24$
weeks' gestation (Grade C).

Return of fertility is rapid following first-trimester abortion and can occur as soon as 2 weeks following abortion. ${ }^{63}$ SPCs do not give advice on starting COCs following 
second-trimester abortion. The SPC for the transdermal combined contraceptive patch suggests it can be started immediately following abortion at $<20$ weeks' gestation to provide immediate contraceptive protection. ${ }^{33}$ If $>20$ weeks' gestation, patch use should be delayed until Day 21 or the first day of menses but no advice is given on condom use.

Advice varies for POPs for women following abortion. Some POPs can be started immediately following firsttrimester abortion 40,41 but condoms are advised for 14 days. The desogestrel-only pill can be started immediately following first-trimester abortion with no need for condoms and can be started following second-trimester abortion 'before menstruation'. Some POPs can be started the day after abortion with immediate contraceptive protection. $39,42,43$

The SPC for progestogen-only implants suggests that an implant can be inserted immediately following firsttrimester abortion but should be delayed until between Days 21 and 28 following second-trimester abortion. ${ }^{49}$ If inserted after Day 28, condoms are required for 7 days.

The SPC for DMPA suggests it can be administered immediately following abortion 52 although heavy or prolonged bleeding may occur. SPCs do not state whether this refers to first- and/or second-trimester abortion. The SPC for NET-EN suggests it can be started immediately following abortion but does not specify gestation. 53

There is little evidence or biological plausibility to suggest that use of progestogen-only methods increases the risk of venous thromboembolism (VTE) ${ }^{64}$ There appears to be no reason to delay insertion following secondtrimester abortion.

The SPC for the LNG-IUS suggests it can be inserted immediately after first-trimester surgical abortion. ${ }^{54}$ No mention is made of medical termination or abortion at other gestations.

The information for the Nova-T 380 supports insertion immediately after first-trimester abortion. Insertion of an IUD immediately following induced abortion has advantages in that the woman is known not be pregnant, is highly motivated and is already attending a health care setting. Systematic reviews (which included devices not currently in use) found that IUD insertion at the time of surgical abortion is safe and practical. ${ }^{65}$ Expulsion rates were higher following insertion at the time of a secondtrimester abortion.

The WHOSPR supports use of COC, POP progestogen-only injectables and implants immediately after abortion without the need for additional contraceptive protection (although gestation is not specified). ${ }^{2}$ The WHOSPR also supports insertion of an IUD or the LNGIUS immediately after first-trimester abortion and generally immediately following second-trimester abortion. ${ }^{2}$

The CEU suggests that the advice is the same for induced or spontaneous abortion at $<24$ weeks' gestation. By 'immediately following abortion' the CEU refers to the day of the surgical abortion procedure or the day of the second part of a medical abortion procedure. The CEU suggests that combined hormonal methods (pills and patch) and progestogen-only methods (pills, injectables and implants) should be started immediately or within 7 days following abortion (induced or spontaneous) at gestations $<24$ weeks to provide immediate contraceptive protection. $6,59,66$ If started after Day 7, additional contraceptive protection is advised for 7 days (or 2 days for POP). The CEU advises that an IUD or the LNG-IUS can be inserted immediately following abortion at $<24$ weeks" gestation.

\section{Postpartum (not breastfeeding)}

12 Contraception is not required before Day 21 postpartum. Ideally, hormonal contraception should be started on Day 21 to provide immediate contraceptive protection. However, progestogenonly methods can be started before Day 21 if requested (Grade C).

13 All intrauterine methods can be inserted from 4 weeks postpartum; they can also be inserted within 48 hours of delivery (Grade C).

The earliest date of ovulation postpartum is believed to be Day 28; with contraceptive methods initiated on Day 21 providing immediate contraceptive protection. A small, prospective, comparative study included 22 postpartum non-breastfeeding women who had daily urine assays performed. ${ }^{67}$ All women menstruated within 12 weeks postpartum and first ovulation occurred on average 45 days postpartum. Another small longitudinal study investigated 30 postpartum women with assessment of salivary progesterone and found that the delivery to menstruation interval was $57( \pm 7)$ days and that ovulation occurred on average at Day 23 ( \pm 7 days) ${ }^{68}$

The SPCs suggest starting COC from Day 21. The SPC for the transdermal contraceptive patch, however, suggests it should not be started until at least 4 weeks postpartum.

The SPCs suggest some POPs can be started 7 days after a vaginal delivery if ambulant, with immediate contraceptive protection. ${ }^{41,40}$ Other SPCs suggest starting on Day 21 to provide immediate protection. $39,41,43,47$ If starting after Day 21, condoms are advised for 7 days.

The SPC for the progestogen-only implant advises insertion between Days 21 and 28 postpartum. 49

The SPC for DMPA suggests initiation within 5 days postpartum. 52

The SPC for the LNG-IUS suggests delaying insertion until 6 weeks postpartum. ${ }^{54}$

The CEU suggests that women can be advised that contraception does not need to be started before Day 21 postpartum. Postpartum women who are not breastfeeding can start COC (licensed) and combined patch (unlicensed) from Day 21 without the need for additional contraceptive protection. 6 Like the WHOSPR, the CEU suggests that POPs and progestogen-only implants can be started $<21$ days postpartum (unlicensed) as can progestogen-only injectables (licensed) if wished. If starting after Day 21, additional contraceptive protection is required for 2 days with POP (unlicensed) or 7 days for progestogen-only injectables and implants. An IUD can be inserted within 48 hours of delivery or from 4 weeks postpartum (unlicensed). ${ }^{2}$ WHO suggests a LNG-IUS should not be inserted immediately and insertion delayed until 4 weeks postpartum (unlicensed). ${ }^{2}$

\section{Breastfeeding}

14 Breastfeeding women can be advised that: combined hormonal contraception can be used from 6 weeks to 6 months postpartum if no other method is acceptable; POPs can be started before Day 21 postpartum but if started after Day 21 additional contraceptive protection is required for 2 days; progestogen-only implants can be inserted before Day 21 postpartum but bleeding may be a problem; progestogen-only injectables can be given $<6$ weeks postpartum but should ideally be delayed until Day 21 postpartum (Good Practice Point). 
'Full breastfeeding' can be 'exclusive' (when no other liquids or solids are given) or 'almost exclusive' (when vitamins, water or juice are given infrequently). 62,69 Women who are fully breastfeeding, amenorrhoeic and $<6$ months postpartum can rely on the lactational amenorrhoea method to provide contraception with over $98 \%$ efficacy. 62,69 Additional contraception is required when breastfeeding frequency decreases (particularly night feeds), menstruation recurs or when $>6$ months postpartum. 62 'Partial' or 'token' breastfeeding can vary from 'high' (where the vast majority of feeds are breastfeeds) to 'minimal' (where there are occasional irregular breastfeeds); this has less or little impact on fertility and additional contraception is advised. ${ }^{62}$

SPCs suggest combined hormonal methods should be avoided when breastfeeding.

SPCs provide limited information on starting POPs in women who are breastfeeding. All highlight minimal effects on breast milk. For breastfeeding women, the use of POP before 6 weeks postpartum may be outside product licence.

The SPC suggests that the progestogen-only implant can be used by breastfeeding women. ${ }^{49}$ However, there is no recommendation on when to initiate this method.

The SPC for DMPA suggests that it can be administered from 6 weeks postpartum if breastfeeding. 52

The CEU has published Guidance on the use of contraception by breastfeeding women. ${ }^{62}$ Combined hormonal contraception should be avoided in the first 6 weeks postpartum due to effects on breast milk and infant growth. Combined hormonal contraception can be used without restriction from 6 months. Although use of combined hormonal contraception is not recommended between 6 weeks and 6 months, if feeding is established and other methods are unacceptable it can be considered (unlicensed). ${ }^{62}$

Studies have not supported a detrimental effect on breast milk or infant growth with POP use ${ }^{62}$ and therefore breastfeeding women can start POP up to Day 21 postpartum (outside licence for some POPs) without the need for additional contraceptive protection. If started after Day 21, additional contraceptive protection is required for 2 days (unlicensed). ${ }^{62}$

The CEU suggests delaying initiation of the progestogen-only implant until Day 21 postpartum if breastfeeding. However, if a woman wishes to have the progestogen-only implant inserted before Day 21 there are no data to suggest that this adversely affects breast milk or infant growth. Women should be advised that bleeding may occur. ${ }^{6}$

If breastfeeding women choose the progestogen-only injectable, this can be given before 6 weeks postpartum However, initiation should ideally be delayed until Day 21 postpartum (unlicensed). ${ }^{62}$

\section{Starting contraception following use of POEC}

15 After POEC use, clinicians and women should discuss and consider individually the option of initiating a regular method of contraception prior to the onset of the next menstruation (Good Practice Point).

The SPC for POEC suggests that its use does not contraindicate the continuation of a regular method of contraception. ${ }^{70}$ The CEU has recommended previously that POEC does not provide effective contraceptive cover for the remainder of the cycle and effective contraception or abstinence must be advised. ${ }^{61}$ The WHOSPR suggests that contraceptive methods can be started at any time in the cycle if it is reasonably certain that the woman is not pregnant. ${ }^{2}$ It would be reasonable to consider initiating a method of contraception following POEC use if abstinence is unlikely or further condom failure or UPSI is a risk. Decisions on starting a method following POEC use should be considered on an individual basis. Following missed pills, women should be advised to resume hormonal contraception at their usual time as long as this is within 12 hours of taking POEC.61 It may be appropriate to initiate hormonal contraception, which can be discontinued should POEC fail and a pregnancy occur. Reassuringly, no hormonal method has been shown to be associated with an increased risk of fetal abnormality. Long-term options such as progestogen-only injectables and implants may be best delayed until the next menses as the associated amenorrhoea may delay the diagnosis of pregnancy. Nevertheless, there may be individual situations where they may be started and the woman followed up for a pregnancy test.

\section{When hormonal contraception is late or missed}

Combined oral contraceptive pill

16 Women can be advised that if one or two 30-35 $\mu \mathrm{g}$ ethinylestradiol (EE)-containing COCs are missed (or one $20 \mu \mathrm{g}$ EE-containing COC): the last missed pill should be taken as soon as remembered; pills should be continued daily at the usual time; additional contraceptive protection is not required; and EC is not indicated (Grade C).

17 Women can be advised that if three 30-35 $\mu \mathrm{g}$ EEcontaining COCs are missed (or two $20 \mu \mathrm{g}$ EE-containing COCs) the last missed pill should be taken as soon as remembered and daily pill taking continued. Additional contraceptive protection, such as condoms, is advised for 7 days. EC is only indicated if pills are missed in Week 1 and UPSI occurred in the pill-free week or in Week 1. If pills are missed in Week 3, the pill-free interval should be omitted (Grade C).

SPCs suggest that a COC is 'late' if $>36$ hours have elapsed since the last COC was taken (i.e. $>12$ hours behind schedule). However, 'missed pill rules' were updated in the WHOSPR 2 and have been endorsed by the FFPRHC ${ }^{71}$ and fpa (summarised in Table 1 and Figure 1). A 'missed pill' is a pill that a woman completely omits to take (i.e. 48 hours have elapsed since the last COC was taken).

COCs reduce gonadotrophins, thus inhibiting ovulation. ${ }^{18}$ Seven consecutive pills are regularly missed in the pill-free interval without losing contraceptive protection. Follicular activity is evident in the pill-free interval but ovulation does not occur. ${ }^{18,72-74}$ Extending the pill-free interval may reduce efficacy but there is wide inter-individual variation. ${ }^{73}$ When pills are missed, the inhibitory effects may be lifted sufficiently for ovulation to occur. Thus, intercourse following missed pills may result in pregnancy. ${ }^{75,76}$ Studies have suggested that missed pills are much more common than reported.77,78 In a study using electronic monitoring of pill-taking, up to $88 \%$ of women missed pills on two or more consecutive days and up to $51 \%$ of women missed at least three pills per cycle, apparently without jeopardising effectiveness. ${ }^{77}$

The CEU endorses WHOSPR recommendations ${ }^{71}$ for missed pills as summarised in the recommendations above. 
CEU GUIDANCE

\begin{tabular}{|c|c|c|}
\hline $\begin{array}{c}\text { If ONE or TWO } 30-35 \mu \mathrm{g} \\
\text { ethinylestradiol (EE) pills have been } \\
\text { missed at any time } \\
\text { OR } \\
\text { ONE } 20 \mu \mathrm{g} \mathrm{EE} \mathrm{pill} \mathrm{is} \mathrm{missed}\end{array}$ & \multicolumn{2}{|c|}{$\begin{array}{c}\text { If THREE or MORE } 30-35 \mu \mathrm{g} \text { EE } \\
\text { pills have been missed at any time } \\
\text { OR } \\
\text { TWO or MORE } 20 \mu \mathrm{g} \text { EE pills are } \\
\text { missed }\end{array}$} \\
\hline \multirow{7}{*}{$\begin{array}{l}\text { She should take the most recent } \\
\text { missed pill as soon she } \\
\text { remembers. } \\
\text { She should continue taking the } \\
\text { remaining pills daily at her usual } \\
\text { time.* } \\
\text { She does not require additional } \\
\text { contraceptive protection. } \\
\text { She does not require emergency } \\
\text { contraception. }\end{array}$} & & \\
\hline & \multirow{5}{*}{\multicolumn{2}{|c|}{$\begin{array}{l}\text { She should take the most recent } \\
\text { missed pill as soon as she } \\
\text { remembers. } \\
\text { She should continue taking the } \\
\text { remaining pills daily at her usual } \\
\text { time.* } \\
\text { She should be advised to use } \\
\text { condoms or abstain from sex until } \\
\text { she has taken pills for } 7 \text { days in a } \\
\text { row. }\end{array}$}} \\
\hline & & \\
\hline & & \\
\hline & & \\
\hline & & \\
\hline & \multicolumn{2}{|c|}{$\begin{array}{l}\text { IN ADDITION } \\
\text { (because extending the pill-free } \\
\text { interval is risky) }\end{array}$} \\
\hline \multicolumn{2}{|c|}{$\begin{array}{l}\text { If pills are missed in Week } 1 \\
\text { (Days } 1-7) \text { (because the } \\
\text { pill-free interval has been } \\
\text { extended) }\end{array}$} & $\begin{array}{l}\text { If pills are missed in Week } 3 \\
\text { (Days 15-21) (to avoid } \\
\text { extending the pill-free } \\
\text { interval) }\end{array}$ \\
\hline \multicolumn{2}{|c|}{$\begin{array}{l}\text { Emergency contraception } \\
\text { should be considered if } \\
\text { she had unprotected sex } \\
\text { in the pill-free interval or } \\
\text { in Week } 1 .\end{array}$} & $\begin{array}{l}\text { She should finish the pills } \\
\text { in her current pack and } \\
\text { start a new pack the next } \\
\text { day; thus omitting the } \\
\text { pill-free interval. }\end{array}$ \\
\hline
\end{tabular}

*Depending on when she remembers her missed pill she may take two pills on the same day (one at the moment of remembering and the other at the regular time) or even at the same time.

Figure 1 Advice for women missing combined oral contraceptives (30$35 \mu \mathrm{g}$ and $20 \mu \mathrm{g}$ ethinylestradiol formulations). Figure reproduced with permission $^{71}$

This advice is outside the terms of product licence for COCs (Figure 1).

\section{Combined contraceptive patch}

Evidence suggests that a combined contraceptive patch can be used for up to 9 days without reducing contraceptive efficacy. ${ }^{79}$ Therefore, if a patch is used for up to an additional 48 hours, no additional contraceptive protection is required if a new patch is then applied. ${ }^{33}$ If, however, this is extended beyond 48 hours, additional contraceptive protection is required for 7 days when the new patch is applied. ${ }^{33}$ When the patch-free interval is extended, SPCs suggest the woman may not be protected from pregnancy. A new patch should be applied and additional contraceptive protection used for 7 days. ${ }^{33}$ In addition, if UPSI occurred during the extended patch-free interval, risk of fertilisation should be considered. These recommendations are within the terms of the product licence.

\section{Progestogen-only pill}

18 Women taking POPs containing levonorgestrel, norethisterone or etynodiol diacetate can be advised that if $>27$ hours have elapsed since taking the last POP (i.e.>3 hours late): the late pill should be taken as soon as remembered; the next pill should be taken at the usual time; additional contraceptive protection such as condoms is advised for 2 days; and if UPSI has occurred in the 2 days since late POP, EC is indicated (Grade C).

19 Women taking desogestrel-only pills can be advised that if $>36$ hours have elapsed since taking the last pill (i.e. $>12$ hours late): the late pill should be taken as soon as remembered; the next pill should be taken at the usual time; additional contraceptive protection such as condoms is advised for 2 days; and if UPSI has occurred in the 2 days since late pills, EC is indicated (Grade C).
SPCs for POPs containing levonorgestrel, norethisterone or etynodiol diacetate suggest if $>3$ hours late (i.e. 27 hours since taking last POP) additional contraceptive protection is required for 7 days. The SPC for the desogestrel-only pill suggests that a desogestrel-only pill is late when $>36$ hours have elapsed since the last pill was taken (i.e. 12 hours late). ${ }^{47}$ But, similarly, additional contraceptive protection is advised for 7 days. The desogestrel-only pill should be treated as other POPs when giving women advice on additional contraceptive protection or need to consider EC. However, this advice does not need to be followed until 12 hours late (i.e. $>36$ hours have elapsed since the last pill was taken).

Studies have suggested that after stopping desogestrelonly pills the minimum time to first ovulation is 7 days and on average is 17.2 days. ${ }^{80}$ An RCT showed that desogestrel-only pills inhibit ovulation in up to $97 \%$ of cycles. Therefore, there are women in whom ovulation can occur and cervical mucus thickening is providing contraceptive efficacy. ${ }^{46}$ POPs thicken cervical mucus and this effect is restored within 48 hours of taking a POP, thus additional contraceptive protection is required for only 2 days following missed or late POPs. EC is indicated if UPSI occurred during these 2 days before cervical mucus effect has peaked (Table 2).

\section{Late progestogen-only injectables}

20 Should a woman present late for her next contraceptive injection (i.e. $>12$ weeks to $<14$ weeks for DMPA, and $>8$ weeks to $<10$ weeks for NETEN) the risk of pregnancy is extremely small. Additional contraceptive protection need not be recommended (Grade C).

The SPC for NET-EN suggests contraceptive efficacy is provided for 8 weeks. ${ }^{53}$ The SPC for DMPA advises that DMPA should be given every 12 weeks. As long as injections are given no later than 5 days after the due date, no additional contraceptive protection is recommended. If the interval from the last injection is greater than 89 days (i.e. 12 weeks and 5 days) then pregnancy should be excluded before the next injection is given and additional contraceptive protection used for 14 days. 52

A small study in three women observed serum medroxyprogesterone concentrations and ovarian activity (by serum progesterone and $\mathrm{LH}$ ) following a single DMPA injection. 81 Concentrations of medroxyprogesterone gradually declined and remained relatively constant at $1 \mathrm{ng} / \mathrm{ml}$ for $2-3$ months, declining thereafter to $0.2 \mathrm{ng} / \mathrm{ml}$ by the sixth month. Concentrations were undetectable at 7-9 months. Serum oestradiol remained at early to midfollicular levels for 4-6 months after the injection. Oestradiol was raised to ovulatory concentrations only when serum medroxyprogesterone concentrations had declined to below $0.25-0.5 \mathrm{ng} / \mathrm{ml}$. In some women, MPA can be identified in serum for as long as 9 months after injection. 82 This would suggest that the DMPA can be given late without the need for additional contraceptive protection as the risk of ovulation is low.

In addition, there is abundant evidence of a delay in return to fertility after discontinuation of DMPA. ${ }^{83} \mathrm{~A}$ total of 796 Thai women stopped using DMPA and 125 had an IUD removed. All were followed up for 2 years. For women discontinuing an IUD the median delay to conception was 4.5 months. For women discontinuing DMPA the median delay was 5.5 months plus the estimated duration of the effect of the last injection, therefore a delay to conception of approximately 9 months can occur in some women. 
The CEU recommends that the progestogen-only injectable DMPA should be given every 12 weeks and NET-EN every 8 weeks. An injection is 'late' when $>12$ weeks (for DMPA) or $>10$ weeks (for NET-EN) have elapsed since the last injection. However, despite late injections, effective contraception is still provided for up to 14 weeks (for DMPA) and to 10 weeks (for NET-EN). After this time, contraceptive protection may be reduced. The CEU supports WHOSPR recommendations that progestogen-only injectables can be given up to 2 weeks late (i.e. an interval of 14 weeks for DMPA and of 10 weeks for NET-EN) without the need for additional contraceptive protection. ${ }^{2}$ Beyond 2 weeks late, protocols for women who attend for progestogen-only injectables should be developed locally and take account of factors such as timing of any UPSI, duration of injectable use, and the presence or absence of amenorrhoea.

\section{When the dose of oral contraceptives is increased}

21 Women taking liver enzyme-inducing drugs who wish to use COC should choose a regimen containing at least $50 \mu \mathrm{g}$ EE daily. Additional contraceptive protection, such as condoms, should be used until 4 weeks after the liver enzymeinducing drug has been stopped (Grade C).

22 Women using POPs containing levonorgestrel, norethisterone or etynodiol diacetate who weigh $>70 \mathrm{~kg}$ are advised to take two pills together every day (Good Practice Point).

Liver enzyme-inducing drugs

It is established UK practice to start a COC with a regimen containing at least $50 \mu \mathrm{g}$ EE daily for women taking liver enzyme-inducing drugs. ${ }^{84-86}$ The most commonly used COC containing $50 \mu \mathrm{g}$ EE (Ovran ${ }^{\circledR}$, Wyeth Laboratories) was discontinued in 2002. An alternative preparation containing $50 \mu \mathrm{g}$ mestranol (Norinyl-1 ${ }^{\circledR}$, Pharmacia) is available. Two studies have provided conflicting evidence on the bioequivalence of $50 \mu \mathrm{g} \mathrm{EE}$ and mestranol. 87,88 Although inter-individual variation may occur, $50 \mu \mathrm{g}$ EE and mestranol have been shown to be comparable. ${ }^{88}$ Liver enzyme-inducers increase the metabolism of oestrogen and progestogen 89 and therefore an increased dose is required. The CEU suggests a regimen of two low-dose COCs (e.g. Loestrin $20^{\circledR}$ plus Loestrin $30^{\circledR}$; Marvelon ${ }^{\circledR}$ plus Mercilon ${ }^{\circledR}$; or two Microgynon $30^{\circledR}$ ), providing a total daily dose of 50-60 $\mu \mathrm{g}$ EE but no trials have compared bioavailability to that of a single tablet. This use is unlicensed. Shortening the pill-free interval has also been advised.

Guidance from the CEU summarised potential drug interaction with liver enzyme-inducers and methods of hormonal contraception. .0 Methods such as POPs and progestogen-only implants are not advised for women using liver enzyme-inducing drugs, while progestogenonly injectables, the LNG-IUS (and IUDs) are unaffected.

\section{Weight over $70 \mathrm{~kg}$}

Some health professionals in the UK advise women weighing $>70 \mathrm{~kg}$ using POPs containing levonorgestrel, norethisterone or etynodiol diacetate to take two pills together every day. Direct evidence to support this practice was not identified. Studies show that obese women who use levonorgestrel implants or vaginal rings 91,92 have higher failure rates than non-obese women. For women using the etonogestrel-only implant, anovulation occurs in $100 \%$ of women. The levonorgestrel-only implant is less reliable in ovulation inhibition, especially in the first years of use. Data may be extrapolated to the effect on weight and POPs containing levonorgestrel, norethisterone and etynodiol diacetate (which are also less reliable at ovulation inhibition). Data from women recruited to an RCT and a non-comparative study were investigated. ${ }^{93}$ Cumulative pregnancy rates differed significantly with body weight at 5 and 7 years of use. Women weighing $\geq 80 \mathrm{~kg}$ experienced relatively higher failure rates. In a multinational study, 1198 women were randomised to Norplant ${ }^{\circledR}$ or Norplant $\mathrm{II}^{\circledR}{ }^{\circledR} .94$ Pregnancies only occurred in Year 5 of use and both pregnancies were in women weighing $>70 \mathrm{~kg}$. Thus women weighing $>70 \mathrm{~kg}$ were more likely to have a method failure than women weighing $<70 \mathrm{~kg} .{ }^{94,95}$ The desogestrel-only pill reliably inhibits ovulation in $97 \%$ of cycles and does not appear to be influenced by weight.

No evidence was identified that taking two POPs per day is harmful and, until further direct evidence is available, the CEU continues to recommend that women weighing $>70 \mathrm{~kg}$ using POPs containing levonorgestrel, norethisterone or etynodiol diacetate should be advised to take two pills together every day (unlicensed). Women using the desogestrel-only pill are advised to take only one pill per day regardless of weight. ${ }^{46}$

\section{When the hormone-free interval is delayed, shortened or omitted}

23 Women may be given advice regarding 'tricycling' combined hormonal contraception to avoid withdrawal bleeds, extending the active hormonetaking days to delay menses, or shortening the pill-free interval if using liver enzyme-inducing drugs (Good Practice Point).

Tricycling

Women can be advised to 'tricycle' packets of COCs for a variety of reasons: to prevent withdrawal bleeds; to reduce menstrual bleeding problems or premenstrual symptoms; and to avoid withdrawal headaches. The regimen is well tolerated and acceptable. Two RCTs have investigated bleeding patterns associated with tricycling COCs. .96 Women taking COCs continuously reported fewer bleeding days requiring sanitary protection, more amenorrhoea, less menstrual pain, and less bloating than women using a 21day COC regimen. ${ }^{97}$ The rate of spotting was the same in the two groups and both groups reported high satisfaction with bleeding patterns. ${ }^{96-98} \mathrm{~A}$ parallel, randomised, multicentre, open-label trial compared two $30 \mu \mathrm{g}$ COCs containing $150 \mu \mathrm{g}$ levonorgestrel. ${ }^{99}$ Women received an extended regimen ( 84 days of active COCs and 7 placebo days) or 13 cycles of the conventional 28-day regime. Unscheduled bleeding occurred in women using the extended regimen but this settled with time. Pregnancy rates and side effects were similar in the two groups. Both regimens were well tolerated.

A small, non-randomised, prospective study reviewed the experiences of 50 women who used their standard COC for 6 weeks followed by a 7-day pill-free interval. ${ }^{100}$ Limited information was obtained due to inherent bias and confounding factors. Nevertheless, many of the women were using $\mathrm{COC}$ for menstrual related symptoms, which were reduced by extending the number of active weeks of pill taking.

There is no evidence that breast cancer or cardiovascular disease is increased with this type of dosing regime. 
The SPCs for COCs suggest they should be taken for 3 weeks followed by a pill-free week (or a placebo pilltaking week). SPCs suggest that the combined hormonal contraceptive patch may be used for up to 6 consecutive weeks before a patch-free week. ${ }^{33}$ In previous Guidance, the CEU supported tricycling COC packs to avoid withdrawal bleeds. ${ }^{6}$ The CEU suggests that patch use may be extended to 12 weeks as for COCs.

\section{Shortening the hormone-free interval}

An alternative regimen to tricycling has been investigated which involves shortening the hormone-free interval by increasing the number of active pills in a packet to 24.101 This has been advocated to reduce the risk of $\mathrm{COC}$ failures for women using liver enzyme-inducing drugs and may be useful for women who have had true pill failures. There is some evidence that reducing the hormone-free interval to 5 days may reduce the risk of ovarian follicular activity. 102

\section{Delaying menses}

A population study found that norethisterone is widely used by women in the UK to delay menstruation ${ }^{103}$ with peak prescribing (1100 items/month/million population) in July. Smaller peaks in prescribing were evident in December and January. Women like to be able to control and delay menses. Combined hormonal contraception can be used to achieve this either by regularly tricycling the $\mathrm{COC}$ or patch or, on occasions, increasing the number of pills or continuing to reapply a new patch each week to delay menses (unlicensed).

\section{Extended use of intrauterine methods}

24 After counselling about declining fertility, contraceptive efficacy and risks associated with IUD insertion, women who have an IUD with $>300 \mathrm{~mm}^{2}$ of copper inserted at age $\geq 40$ years can be advised to retain the device until the menopause (Grade C).

25 Women can be advised that if the LNG-IUS is inserted at $\geq 45$ years of age (and not being used in combination with oestrogen replacement therapy) it may continue to be used to provide contraception for 7 years (Grade $\mathbf{C}$ ).

It is generally accepted that non-hormonal contraception can be stopped 1 year after the last menstrual period (LMP) in a woman $\geq 50$ years of age. ${ }^{104}$ If the LMP occurs in a woman $<50$ years of age, however, contraception should be continued until 2 years of amenorrhoea. 59,105

It is accepted practice that a copper IUD with $\geq 300 \mathrm{~mm}^{2}$ copper which is inserted at $\geq 40$ years can be retained until the postmenopause. ${ }^{59,104}$ This falls outside the manufacturers' recommended duration of use. Women should be counselled about declining fertility with age, the risks associated with insertion (infection, perforation, expulsion) and potential loss of contraceptive efficacy if used beyond the recommended life of the device and be given the choice to continue.

There are data from RCTs of LNG-IUS contraceptive efficacy with 7 years of continuous use. ${ }^{106,107}$ At present, the CEU advises that women aged $\geq 45$ years at the time of LNG-IUS insertion can be counselled regarding ongoing contraceptive efficacy and the risks of removal and replacement and may choose to continue the LNG-IUS for 7 years although this is outside the terms of the product licence. 104
When is POEC used outside the terms of the product licence?

POEC is licensed for use as EC after UPSI or potential contraceptive failure. The current licence for POEC is for a $1.5 \mathrm{mg}$ dose of levonorgestrel to be taken as a single dose as soon as possible and within 72 hours of UPSI or potential contraceptive failure. ${ }^{70,108}$ There are no RCTs to identify the optimal dose of POEC to prevent pregnancy. In addition, there are limited data on how POEC works if ovulation has already occurred. If taken prior to ovulation, POEC can inhibit ovulation for 5-7 days, by which time any sperm in the upper reproductive tract have lost their ability to fertilise an ovum.

\section{Use of POEC beyond 72 hours}

26 POEC may be considered for use between 73 and 120 hours after UPSI, but women should be informed of the limited evidence of efficacy and offered the alternative option of an IUD (Good Practice Point).

Previous CEU Guidance did not support the use of POEC beyond 72 hours. ${ }^{61}$ A large RCT by the WHO ${ }^{109}$ provided evidence that POEC continues to reduce the expected pregnancy rate if taken between 73 and 120 hours after UPSI. Numbers recruited to this arm of the WHO trial were small (214 women between 73 and 120 hours). Between $60 \%$ and $63 \%$ of expected pregnancies were prevented with the divided or the single-dose regimen taken between 73 and 120 hours after UPSI. Although numbers were small and results did not reach statistical significance, these data add weight to the theory that POEC does not suddenly stop working at 72 hours. No data were identified on use of POEC beyond 120 hours.

A randomised, double-blind, placebo-controlled trial ${ }^{110}$ showed that POEC $(1.5 \mathrm{mg}$ levonorgestrel as a divided regimen or $0.75 \mathrm{mg}$ levonorgestrel as a single dose) administered in the follicular phase (pre-ovulation) interferes with the ovulatory process. The efficacy of POEC in inhibiting ovulation depends on the timing of POEC in relation to the pre-ovulatory LH surge. When POEC is given before the LH surge, when follicles are $<15 \mathrm{~mm}$ in size, follicular rupture was prevented or ovulatory dysfunction (absent LH peak or LH peak after follicular rupture) was apparent in the 5 days following administration in between $79 \%$ and $86 \%$ of women. ${ }^{110}$ The larger the follicle at the time of POEC administration the less effective is prevention of follicular rupture. Therefore POEC may still be effective in preventing ovulation if given $>72$ hours after UPSI, particularly if given prior to the LH surge.

\section{Use of POEC more than once in a cycle}

27 Women can be advised that POEC can be used more than once in a cycle if clinically indicated (Good Practice Point).

The SPC states that repeated administration of POEC within a menstrual cycle is not advisable because of the possibility of disturbance of the cycle. ${ }^{70}$ Previous CEU Guidance supported use more than once in a cycle if clinically indicated ${ }^{61}$ It is likely that if POEC is used again prior to the LH surge it will continue to be effective. A randomised, double-blind, placebo-controlled trial showed that when leading follicles did not rupture in the 5 days after taking POEC, ovulation occurred in up to $34.5 \%$ of 
women after this time. ${ }^{110}$ This suggests that further UPSI may be an indication for repeat POEC use.

Use of POEC will not induce abortion if the woman is already pregnant.

Increased dose of POEC for women using liver enzyme-inducers

28 Women using liver enzyme-inducing drugs should
be advised to increase the dose of POEC and take
$2.25 \mathrm{mg}$ as a single dose as soon as possible and
within 72 hours of UPSI (Grade C).

It is established practice in the UK to increase the dose of POEC by $50 \%$ for women using liver enzyme-inducing drugs. ${ }^{6,61}$ This regimen is unlicensed and no studies have confirmed that this dose increase is required. Women should be informed of the lack of data to support the efficacy of POEC when also using liver enzyme-inducing drugs and should be offered an IUD (which is unaffected by concomitant medication). If POEC is chosen, the dose should be increased to $2.25 \mathrm{mg}$. At present, despite lack of evidence, the CEU continues to recommend this increase in dose.

Levonelle One-Step ${ }^{\circledR}$ is available for pharmacy supply (a single tablet of $1.5 \mathrm{mg}$ levonorgestrel) and should be available for NHS supply in Autumn 2005. There is no recommendation in SPCs regarding use for women using liver enzyme-inducing drugs but it is likely that this single tablet $(1.5 \mathrm{mg})$ will be taken as soon as possible and within 72 hours of UPSI sex or potential contraceptive failure and the same dose repeated 12 hours later $(100 \%$ increase in dose) for women using liver enzyme-inducing drugs.

\section{Advance provision of POEC}

29 Advance provision of POEC and instructions on use can be offered to those women attending family planning and sexual health services to increase early use when required (Grade A).

Previous CEU Guidance supports advance provision of POEC for women attending family planning and sexual health services. ${ }^{61}$ Advance provision of POEC refers to provision in advance of need. The SPC provides information on indications for use but does not state that is has to be provided only at the time of unprotected intercourse. It is likely therefore that providing an advanced supply of POEC is not outside the terms of the product licence.

RCTs have shown that in selected women advance provision is safe and effective and increases the early uptake of EC and may reduce the rate of unintended pregnancies without increasing the number of women having UPSI. 111,112 A population-based study did not show that providing sexually active women with EC had any impact on abortion rates. ${ }^{113}$ Nevertheless, advance provision enabled most women who used the supply to do so within 24 hours of UPSI. A recently published RCT that investigated the effect of direct access to EC from pharmacies and advance provision on use of the regimen, pregnancies, sexually transmitted infections, contraceptive use and sexual behaviour 114 found no difference in pregnancy rates between the groups. Women with supplies at home were more likely to use POEC if required without compromising ongoing contraceptive use or sexual behaviour. ${ }^{114}$ Although the CEU does not advocate advance provision of POEC to all women, clinicians may consider advance provision if appropriate (e.g. relying on barrier methods or travelling abroad). What evidence is available to support the use of
contraceptive agents for non-contraceptive unlicensed indications?

Women may use contraception primarily for pregnancy prevention but also gain from non-contraceptive health benefits. ${ }^{6}$ Women who are not at risk of pregnancy may wish to continue their contraceptive method. Women may be not at risk of pregnancy because they are relying on another method of contraception (e.g. sterilisation) but wish to use a contraceptive agent for non-contraceptive benefits. Medical eligibility criteria have been published by the $\mathrm{WHO}^{115}$ and refer to the risk-benefit ratio of contraception for women with certain medical or other conditions. However, these eligibility criteria should be revised if women are using contraception to manage other conditions, since alternative treatment options may also have risks. Contraceptive agents are commonly used in the management of conditions for which there is little published evidence of their effectiveness (e.g. polycystic ovarian syndrome or premenstrual syndrome). Some contraceptives, notably the $\mathrm{COC}$, have been shown to reduce the risk of ovarian ${ }^{116-120}$ and endometrial cancer. ${ }^{118,121-124}$ However, there is insufficient evidence to support the use of COC solely to prevent these cancers. The use of DMPA in women with sickle cell disease has been shown to reduce disease recurrence ${ }^{125}$ and is a suitable contraceptive should one be required. There is insufficient evidence to support use routinely to prevent disease exacerbation.

\section{Combined oral contraception}

Management of menorrhagia

30 Women may be advised that menstrual blood loss may be reduced with COC use (Grade C).

A Cochrane Review concluded that there is insufficient evidence to confirm that $\mathrm{COC}$ reduces menstrual blood loss. ${ }^{126}$ The one small RCT included showed a $43 \%$ reduction in measured menstrual blood loss over two cycles with COC use. ${ }^{127}$ Despite the Cochrane Review, in clinical practice, women almost universally describe less bleeding with $\mathrm{COC}$ use. Guidance from the Royal College of Obstetricians and Gynaecologists (RCOG) supports the use of COC in reducing menstrual bleeding. ${ }^{128}$ In addition, data from small prospective studies confirmed a reduction in menstrual blood loss and dysmenorrhoea in women using oral contraception. ${ }^{129}$ For women with low ferritin at recruitment, concentrations increased with oral contraceptive use. The Oxford Family Planning Association contraceptive study showed that hospital referral for excessive periods, painful periods, irregular periods and other menstrual disorders was only one-half to three-quarters as common in women currently using oral contraceptives or stopping them within the previous 12 months than in non-users. ${ }^{130}$

\section{Management of dysmenorrhoea and endometriosis}

31 Women may be advised that menstrual pain may be reduced with $\mathrm{COC}$ use (Grade $\mathrm{C}$ ).

A Cochrane Review concluded that there was insufficient evidence to determine if $\mathrm{COC}$ use can reduce primary dysmenorrhoea. ${ }^{131} \mathrm{~A}$ subsequent small, randomised, doubleblind, placebo-controlled trial showed a significant reduction in menstrual cramps with oral contraceptive use. ${ }^{132} \mathrm{~A}$ nonsystematic review suggested COC was more effective than placebo in relief of menstrual pain but there was marked heterogeneity between the studies included. ${ }^{131}$ 
A Cochrane Review identified one RCT which suggested COC use was less effective than gonadotrophinreleasing hormone agonists in the relief of menstrual pain associated with endometriosis, but was as effective in reducing dyspareunia and non-menstrual pain. ${ }^{133}$

\section{Management of menstrual bleeding abnormalities} associated with progestogen-only implants or injectables

32 Women using progestogen-only implants or injectables who have menstrual abnormalities may consider the short-term use of a COC or NSAID after gynaecological problems and infection have been excluded (Grade C).

The UK version of WHOSPR recommends use of COC for women with problematic bleeding while using progestogen-only implants or DMPA. ${ }^{3}$ However, supporting evidence is limited. The WHOSPR suggested that treatment of light or heavy bleeding in women using progestogen-only injectables with oestrogen or nonsteroidal anti-inflammatory drugs (NSAIDs) was likely to be of short term or no benefit. EE was moderately effective in decreasing the number of days of bleeding. ${ }^{134}$ The WHOSPR, however, supports the use of NSAIDs (ibuprofen or mefenamic acid), EE or $\mathrm{COC}$ in the management of bleeding associated with progestogen-only implants. ${ }^{2}$ Most data, however, refer to bleeding associated with the levonorgestrel-only implant $\left(\right.$ Norplant $\left.^{\mathbb{R}}\right)$.

\section{Management of acne vulgaris}

33 Women can be informed that COCs improve acne vulgaris (Grade $A)$.

A Cochrane Review highlighted that COCs can improve acne vulgaris. ${ }^{135}$ Small randomised trials have shown significant reductions in acne lesions with COCs containing desogestrel,136,137 levonorgestrel ${ }^{137-140}$ and norgestimate. ${ }^{141}$

Dianette $^{\circledR}$ (Schering Healthcare Ltd) contains $35 \mu \mathrm{g}$ EE with $2 \mathrm{mg}$ cyproterone acetate (a progestogen with antiandrogenic properties). Dianette is not licensed as a contraceptive, but for treatment of acne or hirsutism. A casecontrol study used data from the General Practice Research Database and, after adjustment for body mass index, smoking and androgenic disorders, showed a four-fold increase in the risk of VTE with Dianette compared to a COC containing levonorgestrel (odds ratio 3.9; $95 \%$ CI 1.1-13.4). ${ }^{142}$ Duration of use did not affect this risk. A combined, nested, cohort analysis and case-control study support this level of risk but no randomised trials have been performed, thus confounding and bias cannot be excluded. ${ }^{143}$ The Committee on the Safety of Medicines advised: "Dianette is not indicated solely as a contraceptive; it is a treatment option for women with severe acne, which has not responded to oral antibiotics, or for moderately severe hirsutism; it should be withdrawn 3-4 months after the treated condition has resolved". ${ }^{144}$ If the hyperandrogenism, however, does not resolve and after counselling women may choose to continue or recommence Dianette.

\section{Management of hypo-oestrogenism}

34 Combined hormonal contraception may be useful in preserving bone mineral density (BMD) for women with a premature menopause but has no beneficial effect on BMD in women with anorexia nervosa (Grade B).
Studies have suggested that for women with hypooestrogenism, combined hormonal contraception may be clinically beneficial. The COC appears as effective as hormone replacement therapy (HRT) in preserving or increasing BMD in perimenopausal women. ${ }^{145}$ For women with premature menopause, use of COC may be more acceptable than using a traditional HRT. For women with hypogonadotrophic or normogonadotrophic amenorrhoea there is evidence that $\mathrm{COC}$ use maintains or improves BMD. ${ }^{146}$ For women with anorexia nervosa, however, use of COC has no beneficial effect on BMD.147,148

\section{Progestogen-only pills and implants}

Management of menstrual bleeding

35 POPs and implants are ineffective in the management of menstrual bleeding problems and should not be used for this purpose (Good Practice Point).

There are no recommended uses for POPs or progestogen-only implants other than for contraception. Nevertheless, these methods are used by some women to manage bleeding problems. Women using POC can have a variety of bleeding patterns: regular bleeding, amenorrhoea, infrequent bleeding, frequent or heavy bleeding and prolonged bleeding. Unacceptable bleeding patterns are often given as a reason for discontinuation. ${ }^{35}$ The etonogestrel-only implant is associated with abnormal bleeding: $20 \%$ of implant users will experience amenorrhoea, and up to $45 \%$ have infrequent, frequent or prolonged bleeding. Anovulation occurs throughout the 3 years' duration of use and therefore bleeding patterns are unlikely to change significantly with time. The CEU does not support the use of POPs or progestogen-only implants to improve bleeding patterns for women with abnormal menstrual bleeding.

\section{Progestogen-only injectables}

Management of menorrhagia

36 Progestogen-only injectables can induce
amenorrhoea and may be considered by women
with menorrhagia (Grade B).

Amenorrhoea is reported by almost half (46\%) of DMPA users at 3 months. ${ }^{149}$ This increases with time to $53.3 \%$ at 6 months and 58.5\% at 12 months. Research from the Special Programme of Research and Training in Human Reproduction of the WHO showed that women using DMPA tolerated far greater menstrual disturbances than women using other methods (combined pills, progestogenonly pills and vaginal rings). 150 Women using DMPA were more likely to have been counselled regarding bleeding disturbances than women using other methods, which may explain less discontinuation with DMPA.

Although there are no RCTs investigating DMPA in the management of menorrhagia, it may be helpful for some women.

\section{Levonorgestrel-releasing intrauterine system}

\section{Duration of use in management of menorrhagia}

37 Women can be advised that if the LNG-IUS is used to treat menorrhagia (and when not relying on it for contraception or in combination with oestrogen replacement therapy) then it may be continued beyond the usual 5 years of licensed use, if bleeding patterns remain acceptable (Good Practice Point). 
The LNG-IUS is now licensed for use in idiopathic menorrhagia (5 years) and as protection from endometrial hyperplasia during oestrogen replacement therapy (4 years). 104

\section{References}

World Health Organization (WHO). Selected Practice Recommendations for Contraceptive Use (1st edn). Geneva, Switzerland: WHO, 2004

2 World Health Organization (WHO). Selected Practice Recommendations for Contraceptive Use (2nd edn). Geneva, Switzerland: WHO, 2004. http://www.who.int/reproductivehealth/publications/ rhr_02_7/index.htm.

3 Faculty of Family Planning and Reproductive Health Care (FFPRHC). UK Selected Practice Recommendations for Contraceptive Use. London, UK: FFPRHC, 2002. http://www.ffprhc.org.uk.

4 Glasier A, Brechin S, Raine R, Penney G. A consensus process to adapt the World Health Organization Selected Practice Recommendations for UK use. Contraception 2003; 68: 327-333.

5 British National Formulary, Vol. 48. London, UK: British Medical Association and the Royal Pharmaceutical Association of Great Britain, Association and the Royal
2004. http://www.bnf.org.

6 Faculty of Family Planning and Reproductive Health Care Clinical Effectiveness Unit. FFPRHC Guidance (October 2003). Firs prescription of combined oral contraception. J Fam Plann Reprod Health Care 2003; 29(4): 209-223.

7 Faculty of Family Planning and Reproductive Health Care Clinical Standards Committee. Medicines Management in Contraception, Sexual and Reproductive Health Care Settings (1st edn). London, UK: FFPRHC, 2005 (in press)

8 Royal Pharmaceutical Society of Great Britain. The Safe and Secure Handling of Medicines: A Team Approach. A revision of the Duthie Report (1988) led by the hospitals pharmacists group of the Royal Pharmaceutical Society. London, UK: Royal Pharmaceutical Society of Great Britain, 2005; 1-112.

9 Duthie RB. Guidelines for the Safe and Secure Handling of Medicines (The Duthie Report). London, UK: Department of Health, 1988.

10 General Medical Council (GMC). Good Medical Practice. London, UK: GMC, 2001

11 General Medical Council (GMC). Prescribing Medicines: Frequently Asked Questions. London, UK: GMC, 2005.

12 Department of Health. Crown Report. Review of Prescribing, Supply and Administration of Medicines - Final Report. London, UK: Department of Health, 1998.

13 Scottish Executive Health Department and NHS HDL 2001 (7). Patient Group Directions. Edinburgh, UK: Scottish Executive Health Department, 2001; 1-5

14 Royal Pharmaceutical Society of Great Britain. Fitness to Practise and Legal Affairs Directorate Fact Sheet Five: The Use of Unlicensed Medicines in Pharmacy. 1-4. London, UK: Royal Pharmaceutical Society of Great Britain, 2004.

15 Treloar AE, Boynton RE, Borchild MD, Behn G, Brown BW. Variation of the human menstrual cycle through reproductive life. Int J Fertil 1967: 12: 77-126.

16 Sherman BM, Korenman SG. Hormonal characteristics of the human menstrual cycle throughout reproductive life. J Clin Invest 1975; 55 699-706.

17 Schwarz JL, Creinin MD, Pymar HC, Reid L. Predicting risk of ovulation in new start oral contraceptive users. Am Coll Obstet Gynecol 2002; 99: 177-182.

18 Killick SR, Eyong E, Elstein M. Ovarian follicular development in oral contraceptive cycle. Fertil Steril 1987; 48: 409-413.

19 Lenton EA, Landgren BM, Sexton L, Harper R. Normal variation in the length of the follicular phase of the menstrual cycle: the effect of length of the follicular phase of the menstrual cycle: the
chronological age. Br J Obstet Gynaecol 1984; 91: 681-668.

20 Wilcox AJ, Dunson D, Baird DD. The timing of the "fertile window" in the menstrual cycle: day-specific estimates from a prospective study. BMJ 2000; 321: 1259-1262.

21 Jeyaseelan L, Antonisamy B, Rao PS. Pattern of menstrual cycle length in South Indian women: a prospective study. Soc Biol 1992; 39. 306-309.

22 Sherman BM, Krorenman SG. Measurement of plasma LH, FSH, estradiol and progesterone in disorders of human menstrual cycle: the short cycle. J Clin Endocrinol Metab 1974; 38: 89-93.

23 Parke-Davis. Loestrin: Summary of Product Characteristics (SPCs). 2004. http://www.medicines.org.uk.

24 Organon Laboratories Ltd. Mercilon: Summary of Product Characteristics (SPCs). 2002. http://www.medicines.org.uk.

25 Janssen-Cilag Ltd. BiNovum: Summary of Product Characteristics (SPCs). 2002. http:///www.medicines.org.uk.

26 Janssen-Cilag Ltd. Ovysmen: Summary of Product Characteristics (SPCs). 2002. http://www.medicines.org.uk

27 Janssen-Cilag Ltd. TriNovum: Summary of Product Characteristics (SPCs). 2004. http://www.medicines.org.uk.

28 Organon Laboratories Ltd. Marvelon: Summary of Product Characteristics (SPCs). 2002. http://www.medicines.org.uk.

29 Pharmacia Ltd. Synphase: Summary of Product Characteristics (SPCs). 2004. http://www.medicines.org.uk.
30 Pharmacia Ltd. Brevinor: Summary of Product Characteristics (SPCs) 2002. http://www.medicines.org.uk.

31 Pharmacia Ltd. Norimin: Summary of Product Characteristics (SPCs). 2004. http://www.medicines.org.uk.

32 Janssen-Cilag Ltd. Cilest: Summary of Product Characteristics (SPCs) 2002. http://www.medicines.org.uk.

33 Janssen-Cilag Ltd. EVRA transdermal patch: Summary of Product Characteristics (SPCs). 2003. http://www.medicines.org.uk.

34 Danforth DR, Hodgen GD. "Sunday start" multiphasic oral contraception: ovulation prevention and delayed follicular atresia in primates. Contraception 1989; 39: 321-330.

35 McCann MF, Potter LS. Progestin-only oral contraception: a comprehensive review. Contraception 1994; 50: S159-S188.

36 Kovacs GT, Hendricks J, Summerbell C, Baker WG. A precoital pill? A preliminary in vitro study. Br J Fam Plann 2000; 26: 239.

37 Wyeth Pharmaceuticals. Microval: Summary of Product Characteristics (SPCs). 2003. http://www.medicines.org.uk.

38 Janssen-Cilag Ltd. Micronor HRT: Summary of Product Characteristics (SPCs). 2001. http://emc.medicines org.uk.

39 Pharmacia Ltd. Femulen Tablets: Summary of Product Characteristics (SPCs). 2002. http://www.medicines.org.uk

40 Schering Health Care Ltd. Neogest: Summary of Product Characteristics (SPCs). 2000. http://www.medicines.org.uk.

41 Schering Health Care Ltd. Norgeston: Summary of Product Characteristics (SPCs). 2001. http://www.medicines.org.uk.

42 Pharmacia Ltd. Noriday Tablets: Summary of Product Characteristics (SPCs). 2003. http://www.medicines.org.uk.

43 Janssen-Cilag Ltd. Micronor Oral Contraceptive Tablets: Summary of Product Characteristics (SPCs). 2001. http://www.medicines.org.uk.

44 Faculty of Family Planning and Reproductive Health Care Clinical Effectiveness Unit. New Product Review (April 2003). Desogestrelonly pill (Cerazette). J Fam Plann Reprod Health Care 2003; 29(3): $162-164$.

45 Rice CF, Killick SR, Hickling D, Coelingh Bennink H. Ovarian activity and vaginal bleeding patterns with a desogestrel-only preparation at three different doses. Hum Reprod 1996; 11: 737-740.

46 Rice CF, Killick SR, Dieben TOM, Coelingh Bennink H. A comparison of the inhibition of ovulation achieved by desogestrel 75 microgram and levonorgestrel 30 micrograms daily. Hum Reprod 1999; 14 982-985.

47 Organon Laboratories Ltd. Cerazette: Summary of Product Characteristics (SPCs). 2004. http://.www.medicines.org.uk.

48 Makarainen L, van Beek I, Tuomivaara L, Asplund B, Bennink HC. Ovarian function during the use of a single contraceptive implant: Ovarian function during the use of a single contraceptive impla
Implanon compared with Norplant. Fertil Steril 1998; 68: 714-721.

49 Organon Laboratories Ltd. Implanon: Summary of Product Organon Laboratories Ltd. Implanon: Summary of

50 Petta CA, Faundes A, Dunson TR, Ramos M, DeLucio M, Faundes D, et al. Timing of the onset of contraceptive effectiveness in Depo-Provera users. Part II. Effects on ovarian function. Fertil Steril 1998; 70: $817-820$.

51 Petta CA, Faundes A, Dunson TR, Ramos M, DeLucio M, Faundes D, et al. Timing of the onset of contraceptive effectiveness in Depo-Provers users. Part I. Changes in cervical mucus. Fertil Steril 1998; 69: 252-257.

52 Pharmacia Ltd. Depo-Provera: Summary of Product Characteristics (SPCs). 2004. http://www.medicines.org.uk.

53 Schering Health Care Ltd. Noristerat: Summary of Product Characteristics (SPCs). 2004. http://www.medicines.org.uk.

54 Schering Health Care Ltd. Mirena: Summary of Product Characteristics (SPCs). 2005. http://www.medicines.org.uk.

55 Stanford JB, Mikolajczyk RT. Mechanisms of action of intrauterine devices: update and estimation of postfertilization effects. Am J Obstet Gynecol 2002; 187: 1699-1708.

56 Critchley HOD, Wang H, Jones RL, Kelly RW, Drudy TA, Gebbie AE et al. Morphological and functional features of endometrial decidualization following long-term intrauterine levonorgestrel delivery. Hum Reprod 1998; 13: 1218-1224.

57 Dannemiller Memorial Educational Foundation. The Contraception Report, Modern IUDs Part 2, Vol. 9, No. 5, Grimes DA (ed.) Totowa, NJ: Emron, 1998: 2-16.

58 Segal SJ, Alvarez-Sanchez F, Adejuwon CA, Brache de Mejia V, Leon $\mathrm{P}$, Faundes A. Absence of chorionic gonadotrophin in sera of women who use intrauterine devices. Fertil Steril 1985; 44: 214-218

59 Faculty of Family Planning and Reproductive Health Care Clinical Effectiveness Unit. The copper intrauterine device as long-term contraception. J Fam Plann Reprod Health Care 2004; 30: 29-42.

60 Schering Health Care Ltd. Nova-T 380: Summary of Product Characteristics (SPCs) 1999.

61 Faculty of Family Planning and Reproductive Health Care Clinical Effectiveness Unit. FFPRHC Guidance (April 2003). Emergency Effectiveness Unit. FFPRHC Guidance (April 2003). Emergency
contraception. J Fam Plann Reprod Health Care 2003; 29(2): 9-16.

62 Faculty of Family Planning and Reproductive Health Care Clinical Effectiveness Unit. FFPRHC Guidance (July 2004). Contraceptive choices for breastfeeding women. J Fam Plann Reprod Health Care 2004; 30: 181-189

63 Lahteenmaki P. Postabortal contraception. Ann Med 1993; 25: 185-189. 64 Debert-Ribeiro M, Medina E, Artigas J, He S, Zhong YH, De-Wei Z, et $a l$. Cardiovascular disease and use of oral and injectable progestogen- 


\section{CEU GUIDANCE}

only contraceptives and combined injectable contraceptives: results of an international, multicenter, case-control study. Contraception 1998; 57: $315-324$.

65 Grimes D, Schulz K, Stanwood N. Immediate postabortal insertion of intrauterine devices. Cochrane Database Syst Rev 2004; 18: CD001777.

66 Faculty of Family Planning and Reproductive Health Care Clinica Effectiveness Unit. FFPRHC Guidance (April 2004). The levonorgestrel-releasing intrauterine system (LNG-IUS) in contraception and repr

67 Campbell OM, Gray RH. Characteristics and determinants of postpartum ovarian function in women in the United States. Am J Obstet postpartum ovarian function

68 Bolaji II, Tallon DF, Meehan FP, O’Dwyer EM, Fottrell PF. The return of postpartum fertility monitored by enzyme-immunoassay for salivary progesterone. Gynecol Endocrinol 1992; 6: 37-48.

69 Knight J, Pyper C. Postnatal contraception: what are the choices? Nurs Pract 2002; May: 23-25.

70 Schering Health Care Ltd. New dose instructions for Levonelle-2. 2003. $\mathrm{http}$ ://emc.medicines.org.uk/emc/assets/c/html/displaydoc.asp? documentid=4231.

71 Faculty of Family Planning and Reproductive Health Care Clinical Effectiveness Unit. Faculty Statement from the CEU on a New Publication: WHO Selected Practice Recommendations for Contraceptive Use Update. Missed pills: new recommendations. J Fam Plann Reprod Health Care 2005; 32: 153-155.

72 Smith SK, Kirkman RJ, Arce BB, McNeilly AS, Loudon NB, Baird DT. The effect of deliberate omission of Trinordiol or Microgynon on the hypothalamo-pituitary-ovarian axis. Contraception 1986; 34: 513-522.

73 Killick SR, Bancroft K, Oelbaum S, Morris J, Elstein M. Extending the duration of the pill-free interval during combined oral contraception. Adv Contracept 1990; 6: 33-40.

74 Killick SR. Ovarian follicles during oral contraceptive cycles: their potential for ovulation. Fertil Steril 1989; 52:580-582.

75 Rosenberg MJ, Waugh MS. Causes and consequences of oral contraceptive non-compliance. Am J Obstet Gynecol 1999; 180: 276-279.

76 Rosenburg MJ, Waugh MS, Long S. Unintended pregnancies and use, misuse and discontinuation of oral contraceptives. J Reprod Med 1995 40: $355-360$

77 Potter L, Oakley D, de Leon-Wong E, Canamar R. Measuring compliance among oral contraceptive users. Fam Plann Perspect 1996; 28: $154-158$

78 Aubeny E, Buhler M, Colau JC, Vicaut E, Zadikian M, Childs M. Oral contraception: patterns of non-compliance. The Coraliance Study. Eur J Contracept Reprod Health Care 2002; 7: 155-161.

79 Abrams LS, Skee D, Natarajan J, Wong FA, Anderson CD Pharmacokinetics of a contraceptive patch (Evra/Ortho Evra) containing norelgestromin and ethinyloestradiol at four application sites. $J$ Clin Pharmacol 2001; 53: 141-146.

80 Korver T, Klipping C, Heger-Mahn I, Duijkers I, Van Osta G. Maintenance of consistent ovulation inhibition with the $75 \mu \mathrm{g}$ desogestrel-only contraceptive pill Cerazette after scheduled 12-hour delays in tablet-intake. Eur J Contracept Reprod Health Care 2004; 9: 43 .

81 Oritz A, Hirol M, Stanczyk FZ, Goebelsmann U, Mishell DR. Serum medroxyprogesterone acetate (MPA) concentrations and ovarian medroxyprogesterone acetate (MPA) concentrations and ovarian Endocrinol Metab 1977; 44: 32-38.

82 Mishell DRJ, Kharma KM, Thorneycroft IH, Nakamura RM. Estrogenic activity in women receiving and injectable progestogen fo contraception. Am J Obstet Gynecol 1972; 113: 372-376.

83 Pardthiasong T. Return of fertility after use of the injectable contraceptive Depo-Provera - an updated data analysis. J Biosoc Sci 1984; 16: 23-24

84 American Academy of Neurology. Practice parameter: management issues for women with epilepsy. Report of the Quality Standards Subcommittee of the American Journal of Neurology. Neurology 1998; 51: 944-948.

85 Elliman A. Interactions with hormonal contraception. J Fam Plann Reprod Health Care 2000; 26: 109-111.

86 Crawford P. Interactions between antiepileptic drugs and hormonal contraception. CNS Drugs 2002; 16: 263-272.

87 Goldzieher JW, Brody SA. Pharmacokinetics of ethinyl estradiol and mestranol. Am J Obstet Gynecol 1990; 163: S2114-S2119.

88 Kisicki J. Bioequivalence of Norethin and Ortho-Novum in healthy females. Adv Ther 1989; 6: 261-268.

89 Stockley IH. Stockley's Drug Interactions (6th edn). London, UK: Pharmaceutical Press, 2002.

90 Faculty of Family Planning and Reproductive Health Care Clinical Effectiveness Unit. FFPRHC Guidance (April 2005). Drug interactions with hormonal contraception. J Fam Plann Reprod Health Care 2005; 31: $139-151$.

91 Sivin I. International experience with Norplant and Norplant-2 contraception. Stud Fam Plann 1988; 19: 81-94.

92 Koetsawang S World Health Organization Task Force on Long-Acting Systemic Agents for Fertility Regulation. Microdose intravaginal levonorgestrel contraception: a multicentre clinical trial. III. The relationship between pregnancy rate and body weight. Contraception 990; 41: 143-150

93 Sivin I, Mishell DRJ, Diaz S, Biswas A, Alvarez F, Darney P, et al. Prolonged effectiveness of Norplant capsule implants: a 7-year study. Contraception 2000; 61: 187-194

94 Sivin I, Campodonico I, Kiriway O. The performance of levonorgestrel rod and Norplant contraceptive implant: a 5-year randomised study. Hum Reprod 1998; 13: 3371-3378.

95 Glasier A. Implantable contraceptives for women; effectiveness, discontinuation rates, return to fertility, and outcomes of pregnancy. Contraception 2002; 65: 29-37.

96 Miller L, Notter K. Menstrual reduction with extended use of combination oral contraceptive pills: randomized controlled trial. Obstet Gynecol 2001; 98: 771-778.

97 Kwiecien M, Edelman A, Nichols MD, Jensen JT. Bleeding patterns and patient acceptability of standard or continuous dosing regimens of a low-dose oral contraceptive: a randomized trial. Contraception 2003; 67: 9-13.

98 Miller L, Hughes JP. Continuous combination oral contraceptive pills to eliminate withdrawal bleeding: a randomized trial. Obstet Gynecol 2003; 101: 653-661.

99 Anderson FD, Hait H. A multicenter, randomized study of an extended cycle oral contraceptive. Contraception 2003; 68: 89-96.

100 Sulak PJ, Cressman BE, Waldrop E, Holleman S, Juehl TJ. Extending the duration of active oral contraceptive pills to manage hormone withdrawal symptoms. Obstet Gynecol 1997; 89: 179-183.

101 Creinin MD, Lippman JS, Eder SE, Godwin A, Olson W. The effect of extending the pill-free interval on follicular activity: triphasic norgestimate/35 $\mu \mathrm{g}$ ethinyl estradiol versus monophasic levonorgestrel/20 $\mu \mathrm{g}$ ethinyl estradiol. Contraception 2002; 66 $147-152$.

102 Spona J, Elstein M, Feichtinger W, Sullivan H, Ludicke F, Muller U, et $a l$. Shorter pill-free interval in combined oral contraceptives decreases follicular development. Contraception 1996; 54: 71-77.

103 Shakespeare J, Neve E, Hodder K. Is norethisterone a lifestyle drug? Results of database analysis. BMJ 2000; 320: 291

104 Faculty of Family Planning and Reproductive Health Care Clinical Effectiveness Unit. FFPRHC Guidance (January 2005). Contraception for women aged over 40 years. J Fam Plann Reprod Health Care 2005 31: $51-64$

105 Brechin S, Gebbie A. Perimenopausal contraception. A Faculty Aid to Continued Professional Development Topic. J Fam Plann Reprod Health Care 2000; 25: 1-8.

106 Sivin I, Stern J, Coutinho E, Mattos CER, el Mahgoub S, Diaz S, et al. Prolonged intrauterine contraception: a seven-year randomized study of the levonorgestrel $20 \mathrm{mcg} / \mathrm{day}$ ( $\mathrm{LNg} 20$ ) and the copper T380 Ag IUDs. Contraception 1991; 44: 473-480.

107 Sivin I, Diaz J, Alvarez F, Branche V, Diaz S, Pavez M, et al. Four-year experience in a randomized study of the Gyne $T \AA 380$ slimline and the standard Gyne $\mathrm{T}^{\circledR} 380$ intrauterine copper devices. Contraception 1993 47: $37-42$.

108 Chief Medical Officer (CMO). Levonelle/Levonelle 2 emergency contraception: new advice. CMO Update 35. 2003. London, UK: Department of Health, 2003. http://www.doh.gov.uk/cmo/ cmo_35.htm.

109 von Hertzen H, Piaggio G, Ding J, Chen J, Song S, Bartfai G, et al. Low dose mifepristone and two regimens of levonorgestrel for emergency contraception: a WHO multicentre randomised trial. Lancet 2002; 360: $1803-1810$.

110 Croxatto HB, Brache V, Pavez M, Cochon L, Forcelledo ML, Alvarez F, et al. Pituitary-ovarian function following the standard levonorgestrel emergency contraceptive dose or a single $0.75-\mathrm{mg}$ dose given on the days preceding ovulation. Contraception 2004; 70: 442-450.

111 Glasier A, Baird D. The effects of self-administering emergency contraception. N Engl J Med 1998; 339: 1-4.

112 Ellertson C, Ambardekar S, Hedley A, Coyaji K, Trussell J, Blanchard K. Emergency contraception: randomized comparison of advance provision and information only. Obstet Gynecol 2001; 98: 570-575.

113 Glasier A, Fairhurst K, Ziebland S, Seaman P, Walker J, Lakha F. Advanced provision of emergency contraception does not reduce Advanced provision of emergency contraception

114 Raine T, Harper C, Rocca CH, Fischer R, Padian N, Klausner JD, et al. Direct access to emergency contraception through pharmacies and effect on unintended pregnancy and STIs. JAMA 2005; 293: 54-62.

115 World Health Organization (WHO). Medical Eligibility Criteria for Contraceptive Use (3rd edn). Geneva, Switzerland: WHO, 2004

116 Siskind V, Green A, Bain C, Pudie D. Beyond ovulation: oral contraceptives and epithelial ovarian cancer. Epidemiology 2000; 11: 106-110.

117 The Cancer and Steroid Hormone Study of the Centers for Disease Control and the National Institute of Child Health and Human Development. The reduction in risk of ovarian cancer associated with oral-contraceptive use. N Engl J Med 1987; 316: 650-655.

118 Vessey M, Painter R, Yeates D. Mortality in relation to oral contraceptive use and cigarette smoking. Lancet 2003; 362: 185-191.

19 International Agency for Research on Cancer (IARC). Monographs on the Evaluation of Carcinogenic Risks to Humans. Hormonal Contraception and Postmenopausal Hormonal Therapy. Lyons, France: WHO IARC, 1999. 
120 Narod SA, Risch H, Moslehi R, Dorum A, Neuhausen S, Olsson H, et al. Oral contraceptives and the risk of hereditary ovarian cancer. N Engl J Med 1998; 339: 424-428.

121 Cancer and Steroid Hormones (CASH). Combined oral contraceptive use and risk of endometrial cancer. JAMA 1987; 257: 796-800.

122 Jick SS, Walker AM, Jick H. Oral contraceptives and endometrial cancer. Obstet Gynecol 1993; 82: 931-935.

123 The Cancer and Steroid Hormone Study of the Centers for Disease Control and the National Institute of Child Health and Human Development. Combination oral contraceptive use and the risk of endometrial cancer. JAMA 1987; 257: 796-800.

124 Weiderpass E, Adami H, Baron JA, Magnusson C, Lindgren A, Persson I. Use of oral contraceptives and endometrial cancer risk (Sweden). Cancer Causes Control 1999; 10: 277-284.

125 De Ceulaer K, Gruber C, Hayes R, Serjeant GR. Medroxyprogesterone acetate and homozygous sickle-cell disease. Lancet 1982; 2: 229-231.

126 Iyer V, Farquhar C, Jepson R. Oral contraceptive pills for heavy menstrual bleeding. Cochrane Database Syst Rev 2000; 2: CD000154

127 Fraser I, McCarron G. Randomised trial of 2 hormonal and 2 prostaglandin-inhibiting agents in women with a complaint of menorrhagia. Aust N Z J Obstet Gynaecol 1991; 31: 66-70

128 Royal College of Obstetricians and Gynaecologists (RCOG). The Management of Menorrhagia in Secondary Care (National EvidenceBased Clinical Guidelines). London, UK RCOG, 1999.

129 Larsson G, Milsom I, Lindstedt G, Rybo G. The influence of a low-dose combined oral contraceptive on menstrual blood loss and iron status. Contraception 1992; 46: 327-334.

130 Vessey M, Painter R, Mant J. Oral contraception and other factors in relation to hospital referral for menstrual problems without known underlying cause: findings in a large cohort study. Br J Fam Plann 1996; 22: $166-169$

131 Proctor ML, Roberts H, Farquhar CM. Combined oral contraceptive pill (OCP) as treatment for primary dysmenorrhoea. Cochrane Database Syst Rev 2001; 4: CD002120.

132 Hendrix SL, Alexander NJ. Primary dysmenorrhea treatment with a desogestrel-containing low-dose oral contraceptive. Contraception 2002; 66: 393-399.

133 Moore J, Kennedy S, Prentice A. Modern combined oral contraceptives for pain associated with endometriosis. Cochrane Database Syst Rev 2000; 2: CD001019.

134 Said S, Sadek W, Rocca M, Koetsawang S, Kirwat O, Piya-Anant M, et al. Clinical evaluation of the therapeutic effectiveness of ethinyl oestradiol and oestrone sulphate on prolonged bleeding in women using depot medroxyprogesterone acetate for contraception. World Health evelopment and Research Training in Human Reproduction, Task Force on Long-acting Systemic Agents for Fertility Regulation. Hum Reprod 1996; 11(Suppl. 2): $1-13$.

135 Arowojolu AO, Gallo MF, Grimes DA, Garner SE. Combined oral contraceptive pills for treatment of acne. Cochrane Database Syst Rev 2004; 3: CD004425.

136 Vartiainen M, de Gazelle H, Broekmeulen CJ. Comparison of the effect on acne with a combiphasic desogestrel-containing oral contraceptive and a preparation containing cyproterone acetate. Eur J Contracept
Reprod Health Care 2001; 6: 46-53.

137 Rosen MP, Breitkopf DM, Nagamani M. A randomized controlled trial of second- versus third-generation oral contraceptives in the treatment of acne vulgaris. Am J Obstet Gynecol 2003; 188: 1158-1160

138 Worret I, Arp W, Zahradnik HP, Andreas JO, Binder N. Acne resolution rates: results of a single-blind, randomized, controlled, parallel phase three trial with EE/CMA (Belara) and EE/LNG (Microgynon). Dermatology 2001; 203: 38-44.

139 Leyden J, Shalita A, Hordinskly M, Swinyer L, Stanczyk FZ, Weber ME. Efficacy of a low dose oral contraceptive containing 20 microg of ethinyl oestradiol and 100 microg of levonorgestrel for the treatment of moderate acne: a randomized placebo-controlled trial. J Am Acad Dermatol 2002; 47: 399-409.

140 Thiboutot D, Archer DF, Lemay A, Washenik K, Roberts J, Harrison DD. A randomized, controlled trial of a low-dose contraceptive containing $20 \mu \mathrm{g}$ of ethinyl estradiol and $100 \mathrm{mg}$ of levonorgestrel for acne treatment. Fertil Steril 2001; 76: 461-468.

141 Redmond GP, Olson WH, Lippman JS, Kafrissen ME, Jones TM, Jorizzo JL. Norgestimate and ethinyl oestradiol in the treatment of acne vulgaris: a randomized, placebo-controlled trial. Obstet Gynecol 1997; 89: $615-622$

142 Vasilakis-Scaramozza C, Jick H. Risk of venous thromboembolism with cyproterone or levonorgestrel contraceptives. Lancet 2001; 358 $1427-1429$.

143 Seaman HE, Vries CS, Farmer RD. The risk of venous thromboembolism in women prescribed cyproterone acetate in combination with ethinyl estradiol: a nested cohort analysis and casecontrol study. Hum Reprod 2003; 18: 522-526.

144 Committee on Safety of Medicines (CSM). Cyproterone acetate (Dianette): risk of venous thromboembolism (VTE). Curr Problem Pharmacovigilance 2002; 28: 9-10.

145 Taechakraichana N, Limpaphayom K, Ninlagarn T, Panyakhamlerd K, Chaikittisilpa S, Dusitsin N. A randomized trial of oral contraceptive and hormone replacement therapy on bone mineral density and coronary heart disease risk factors in postmenopausal women. Am Coll Obstet Gynecol 2000; 95: 87-94.

146 Castelo-Branco C, Vicente JJ, Pons F, Martinez de Osaba MJ, Casals E, Vanrell JA. Bone mineral density in young, hypothalamic oligomenorrhoeic women treated with oral contraceptives. $J$ Reprod Med 2001; 46: 875-879

147 Munoz MT, Morange-Ramos I, Garcia-Centenera JA, Hervas F, Pozo J, Argenet $\mathrm{J}$. The effects of estrogen administration on bone mineral density in adolescents' anorexia nervosa. Eur J Endocrinol 2002; 146: 45-50.

148 Gordon CM, Grace E, Emans SJ. Effects of dehydroepiandrosterone on bone density in young women with anorexia nervosa. J Clin Endocrinol Metab 2002; 87: 4935-4941.

149 Sangi-Haghpeykar H, Poindexter AN III, Bateman L, Ditmore JR. Experiences of injectable contraceptive users in an urban setting. Obstet Gynecol 1996; 88: 227-233.

150 Belsey EM. The association between vaginal bleeding patterns and reasons for discontinuation of contraceptive use. Contraception 1988 38: $207-225$

This Guidance was developed by the Clinical Effectiveness Unit (CEU) of the Faculty of Family Planning and Reproductive Health Care (FFPRHC): Dr Gillian Penney (Director), Dr Susan Brechin (Co-ordinator); Ms Lisa Allerton (Research Assistant) in consultation with a multidisciplinary expert group of health care professionals involved in family planning and reproductive health care. The expert group comprised: Dr Caroline Boorer (Associate Specialist, Contraception and Sexual Health, Northumberland Health Care); Ms Lorraine Forster (Practice Development Nurse, The Sandyford Initiative, Glasgow); Dr Alyson Elliman (Lead Associate Specialist, Croydon PCT/FFPRHC Clinical Standards Committe Member); Professor Anna Glasier (Reproductive Health, Edinburgh/Chairperson of the Clinical Effectiveness Committee); Dr Sarah Hughe (Consultant in Sexual and Reproductive Health, Centre for Contraception and Sexual Health, Nottingham); Dr Louise Massey (Locum Consultant in Public Health, Wyre Forest PCT, Brook House, Kidderminster/Trainee Member of the CEU/FFPRHC Education Committee Member); Dr Noel Mack (General Practitioner, Kemnay, Aberdeenshire); Ms Elaine Ross (Community Services Pharmacist, Medicine Unit, Westholme, Woodend Hospital, Aberdeen); Dr Rachel Westwick (Career Grade Trainee, Margaret Pyke Centre, London/FFPRHC Education Committee Member). Written feedback was provided by: Ms Toni Belfield (Director of Information, fpa, London).

This Guidance is also available online at http://www.ffprhc.uk. Evidence tables are available on the FFPRHC website. These summarise relevant published evidence on use of contraception outside product licence, which was identified and appraised in the development of this Guidance. The clinical recommendations within this Guidance are based on evidence whenever possible.

\begin{tabular}{|ll|}
\hline \multicolumn{3}{|c|}{ Grades of Recommendations } \\
\hline A & Evidence based on randomised controlled trials (RCTs) \\
\hline B & Evidence based on other robust experimental or observational studies \\
\hline C & Evidence is limited but the advice relies on expert opinion and has the endorsement of respected authorities \\
\hline & Good Practice Point where no evidence exists but where best practice is based on the clinical experience of the expert group
\end{tabular}

Electronic searches were performed for: MEDLINE (CD Ovid version) (1996-2005); EMBASE (1996-2005); PubMed (1996-2005); The Cochrane Library (to February 2005) and the US National Guideline Clearing House. The searches were performed using relevant medical subject headings $(\mathrm{MeSH})$, terms and text words. The Cochrane Library was searched for systematic reviews, meta-analyses and controlled trials relevant to use of contraceptive methods for contraception and other conditions outside the terms of the product licence. Previously existing guidelines from the FFPRHC, the Royal College of Obstetricians and Gynaecologists (RCOG), the World Health Organization (WHO), the Department of Health, the British Medical Association (BMA), the Royal College of Nursing (RCN), the Royal College of General Practitioners (RCGP) and reference lists of identified publications were also searched. Similar search strategies have been used in the development of other national guidelines. Selected key publications were appraised according to standard methodological checklists before conclusions were considered as evidence. Evidence was graded as above, using a scheme similar to that adopted by the RCOG and other guideline development organisations. 